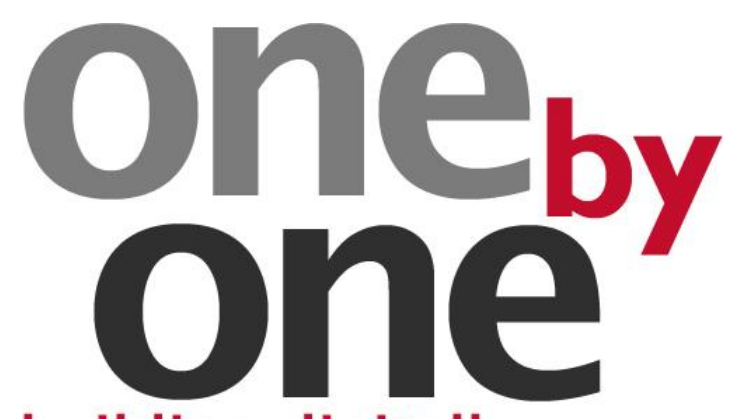

building digitally

confident museums

\title{
Mapping the Museum Digital Skills Ecosystem Phase One Report
}

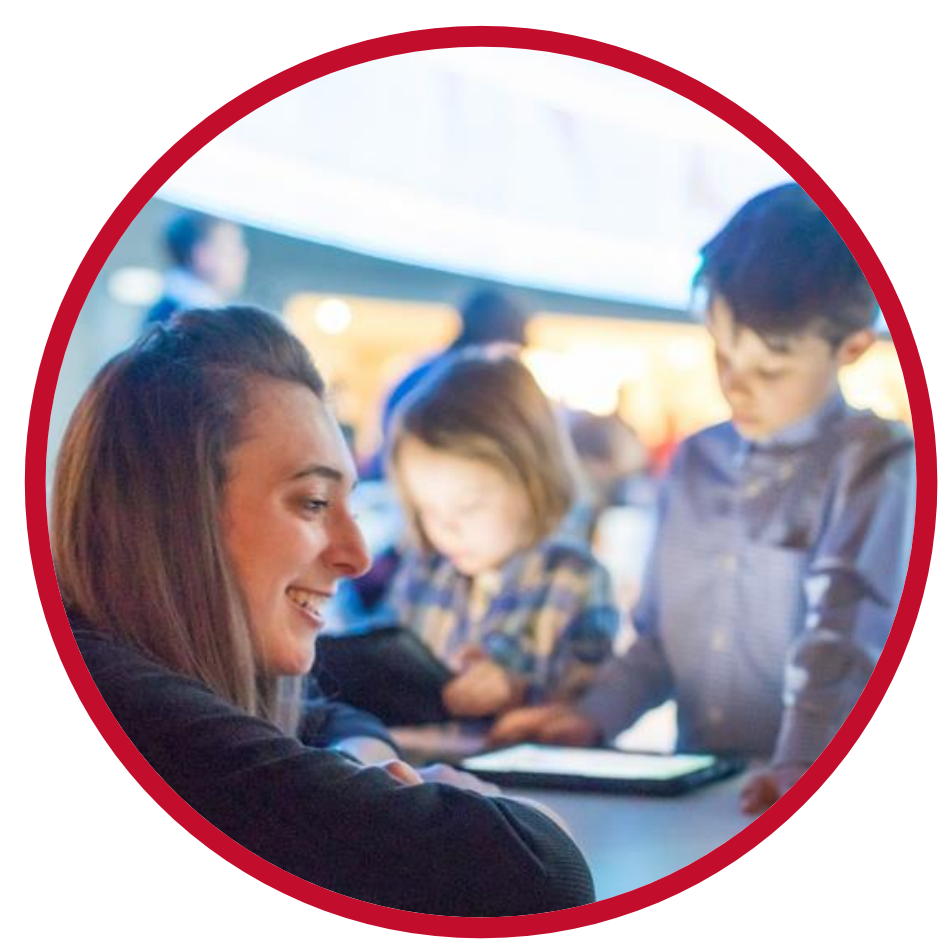


First published 2018

by University of Leicester

University Road, Leicester LE1 7RH

(C)2018 University of Leicester

ISBN: 978-0-9933380-8-3

DOI: https://doi.org/10.29311/2018.01

one-by-one.uk

Picture credits: Museum of London; National Museums Scotland; Connor Carter.

Authored by:

\section{Sally-Anne Barnes \& Erika Kispeter}

Institute for Employment Research, University of Warwick

\section{Doris Ruth Eikhof}

CAMEo Research Institute, University of Leicester

Ross Parry (Project lead)

School of Museum Studies, University of Leicester
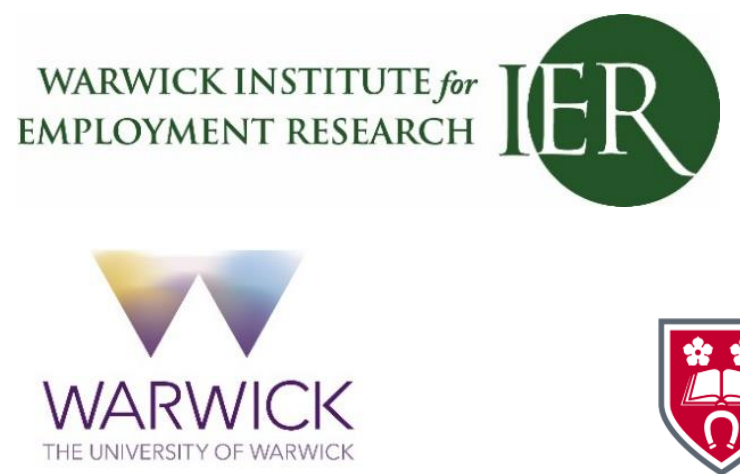

\section{Acknowledgements}

The authors are grateful to the UK's Arts and Humanities Research Council (AHRC) for their generous funding of the 'One by One' national digital literacy project (2017-2020).

We would like to send our appreciation to the following who were instrumental in supporting the fieldwork for Phase one of 'One by One': Dafydd James and colleagues, Amgueddfa Cymru - National Museum Wales; Association of Independent Museums; Bridport Museum; Britten-Pears Foundation; Hannah Fox and colleagues, Derby Museums; Museum Development Network; Frazer Swift, Gemma George-Lawrence and colleagues, Museum of London; Ian Maine and colleagues, National Army Museum; Rob Cawston and colleagues, National Museums Scotland; National Paralympic Heritage Trust; Kevin Bacon and colleagues, Royal Pavilion and Museums Brighton and Hove. 


\section{One one \\ building digitally confident museums}

\section{'One by One' is a national research project which aims to help UK museums of any size better define, improve, measure and embed the digital literacy of their staff and volunteers in all roles and at all levels.}

By introducing a new approach to digital literacy understanding and development, the project's objective is to create new organisational mindsets in museums to help support their digital transformation needs. Digital literacies are defined as 'capabilities which fit an individual for living, learning and working in a digital society. Digital literacy looks beyond functional IT skills to describe a richer set of digital behaviours, practices and identities' (Jisc, 2014).

The project advocates the use of human-centred design principles, and this is demonstrated within the project's own methodology: empathising with museum needs, through researching existing museum digital skills provision; defining what museum digital literacies are required to meet museum needs; ideating and prototyping a practical model of digital literacy-building within museums; testing out the prototype model within partner museums of different functions, sizes and locations; and then sharing the final proposed museum digital literacy framework with the sector.

'One by One' is funded by the Arts and Humanities Research Council (AHRC) and is led by the University of Leicester in partnership with Culture24, together with a range of museum and academic partners: National Museum Wales; National Museums Scotland; National Army Museum; Museum of London; Derby Museums; Royal Pavilion and Museums

Brighton and Hove; CAMEo (the Research Institute for

Cultural and Media Economies), University of Leicester; and the Institute for Employment Research, University of Warwick.

In addition, the project has gathered an important group of strategic stakeholders to represent the needs of all museums, provide vital advisory support, and to share and implement the project's key findings: Arts Council England; Museums Association; Association of Independent Museums; Museum Development Network; Heritage Lottery Fund; National Museum Directors' Council; Collections Trust; and Nesta (a global innovation foundation).

The project began in September 2017 and is due to complete in March 2020. one-by-one.uk $\bullet$

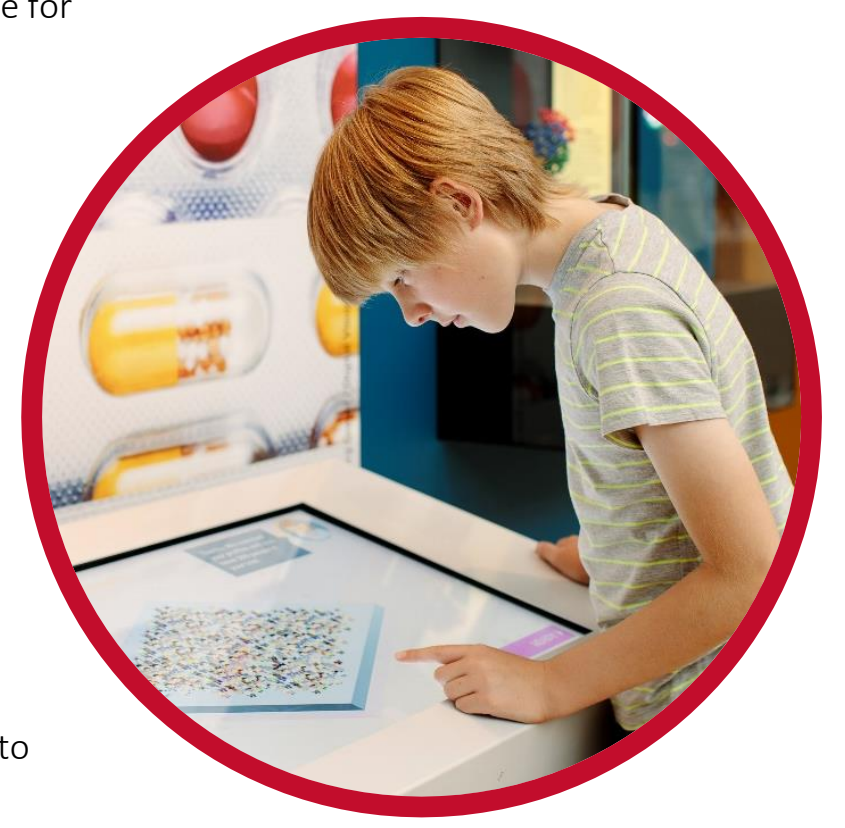




\section{Contents}

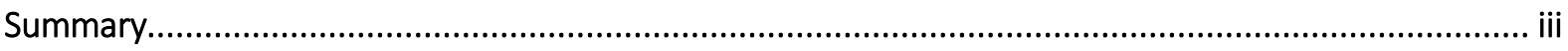

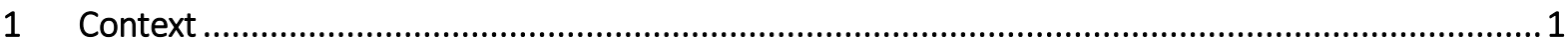

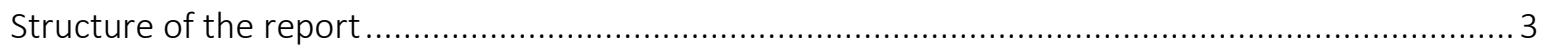

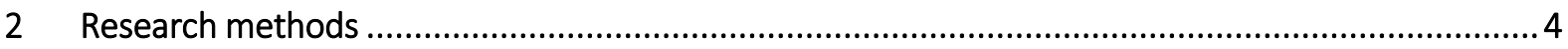

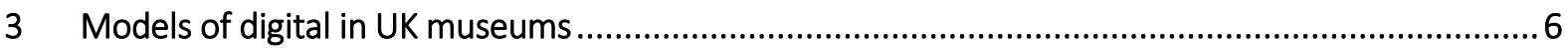

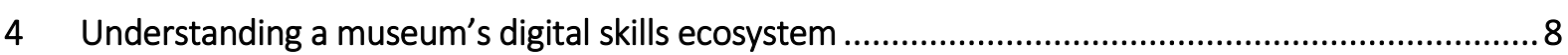

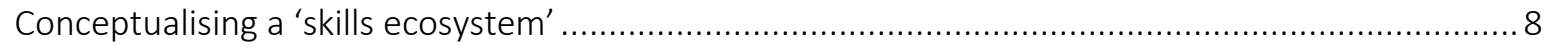

Understanding the skills ecosystem in the context of the museum sector ...............................9

5 Understanding digital skills in the UK museums sector .................................................... 12

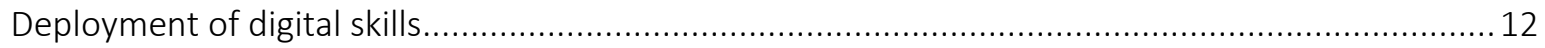

Exemplar projects deploying digital skills and competencies ........................................... 12

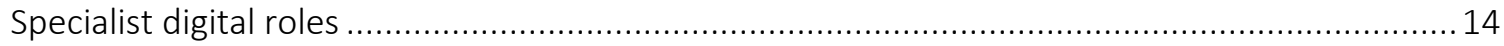

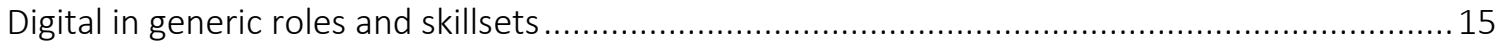

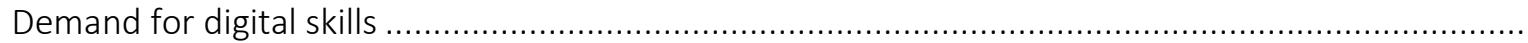

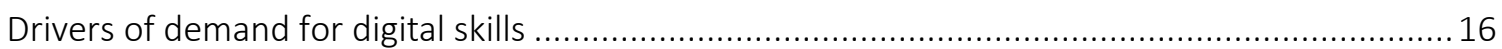

Role changes and the demand for digital skills....................................................... 18

Digital understanding and literacy demands .............................................................. 20

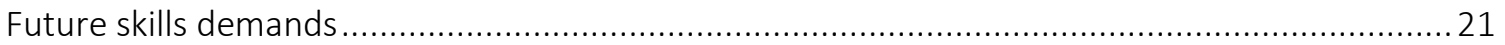

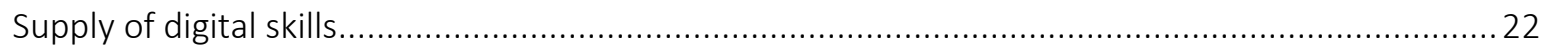

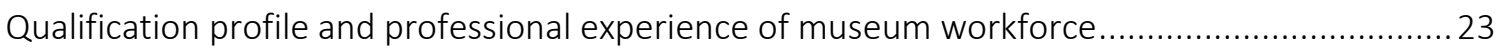

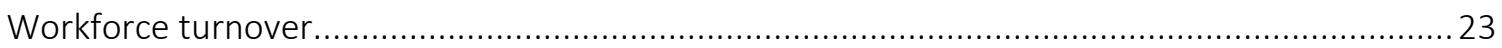

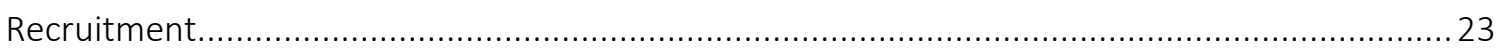

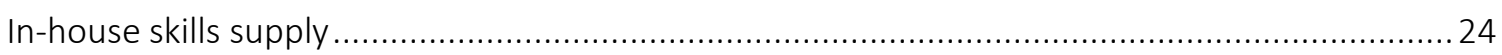

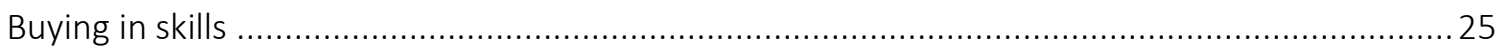

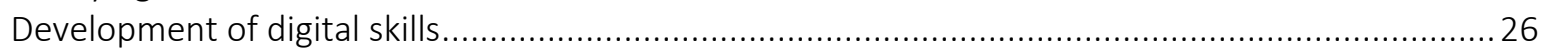

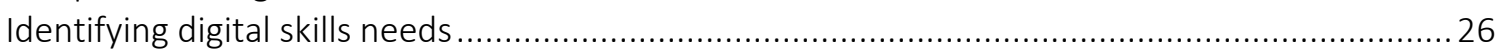

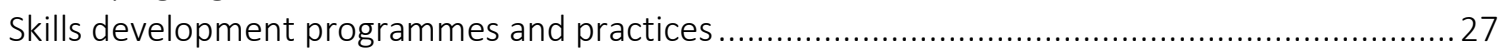

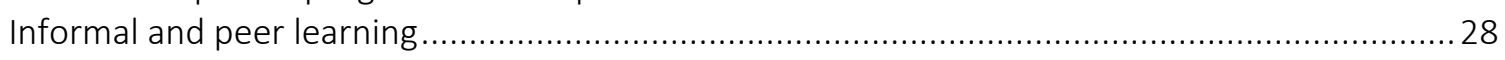

Partnerships, professional networks and conferences................................................ 29

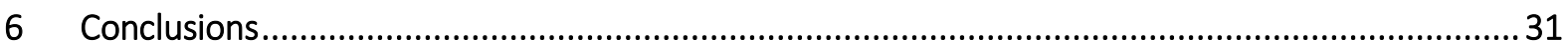

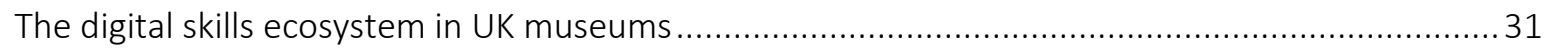

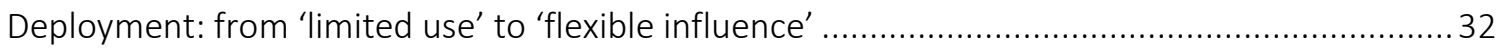

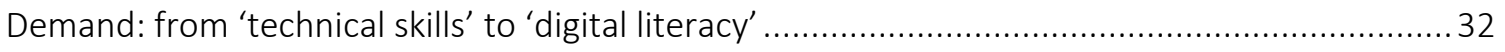

Supply: from 'qualifications and expertise' to 'competence and confidence' ..........................33

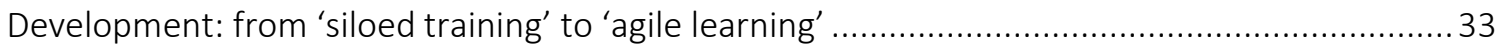

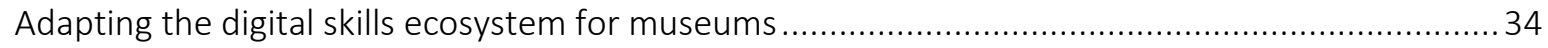

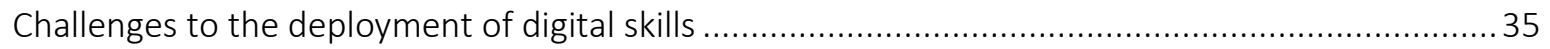

Challenges to developing digital skills and literacies ....................................................... 36

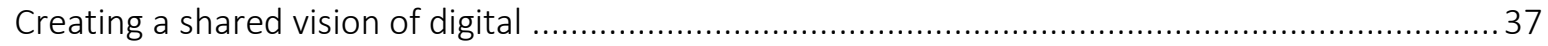

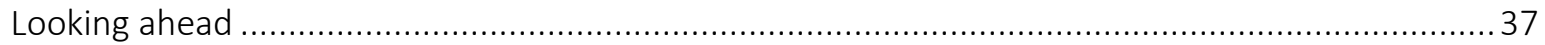

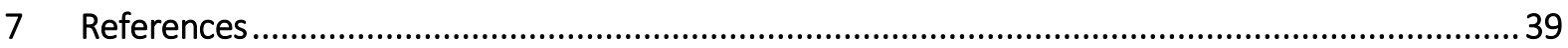

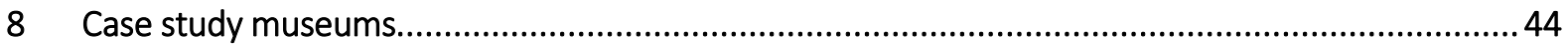

Amgueddfa Cymru - National Museum Wales .............................................................. 44 


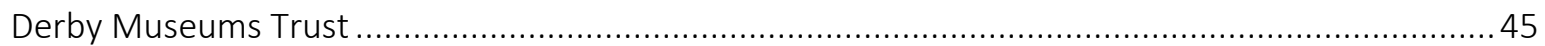

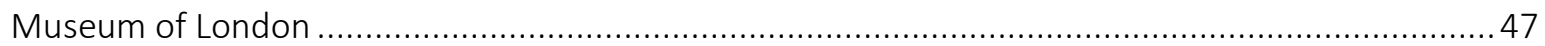

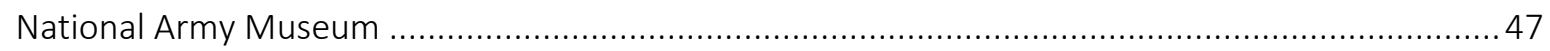

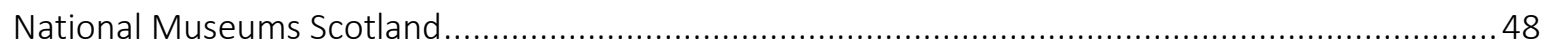

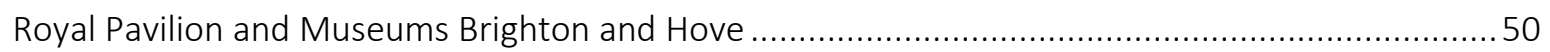

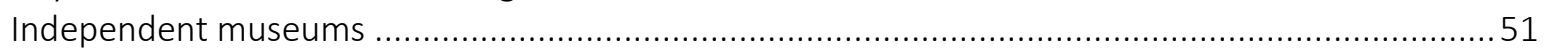

\section{Tables and Figures}

Table 1 Models of digital distribution across UK museums...................................................................

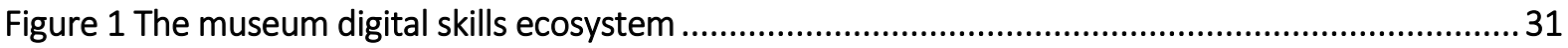




\section{Summary}

'One by One' leverages interdisciplinary scholarship to understand how to deliver a transformative framework for museum workforce digital literacy. The objective of the first phase of the project has been to map how digital skills are currently supplied, developed and deployed in the UK museum sector, and to pinpoint current changes in the demand around these skills.

Key findings:

- There are different practices in how digital responsibilities and skills are distributed, managed and shared across UK museums. Three models were found that exemplify the patterns of digital engagement, how organisational structures and digital responsibilities are evolving, and what this means in practice for digital skills.

See section 3

- Digital is increasingly seen as part of everyone's skill set and all roles have some kind of digital element. Digital skills are not in ready supply throughout the workforce. Using, translating and developing in-house skills is a dominant approach to supplying digital skills. This is being achieved through internal recruitment, informal development and, to a limited extent, formal training.

See section 5

- Digital is becoming professionalised in the museum as digital roles and responsibilities become standard practice. This denotes a shift from responsibility for digital as an 'add-on' to people's roles, towards dedicated digital roles and the democratisation of digital.

See section 5

- As digital becomes institutionalised, museums are restructuring and evolving. There has been the introduction of new roles and departments, as well as changes to existing roles and a greater demand for digital skills. The distinction between specialist digital roles and other roles is becoming blurred.

See section 5

- Museums are exploring, learning and demanding new digital skills as they innovate and create with digital.

See section 5

- There is a deeper understanding by museums of the digital skills, knowledge and expertise needed, as they reflect on the current and potential future of the museum. See section 5

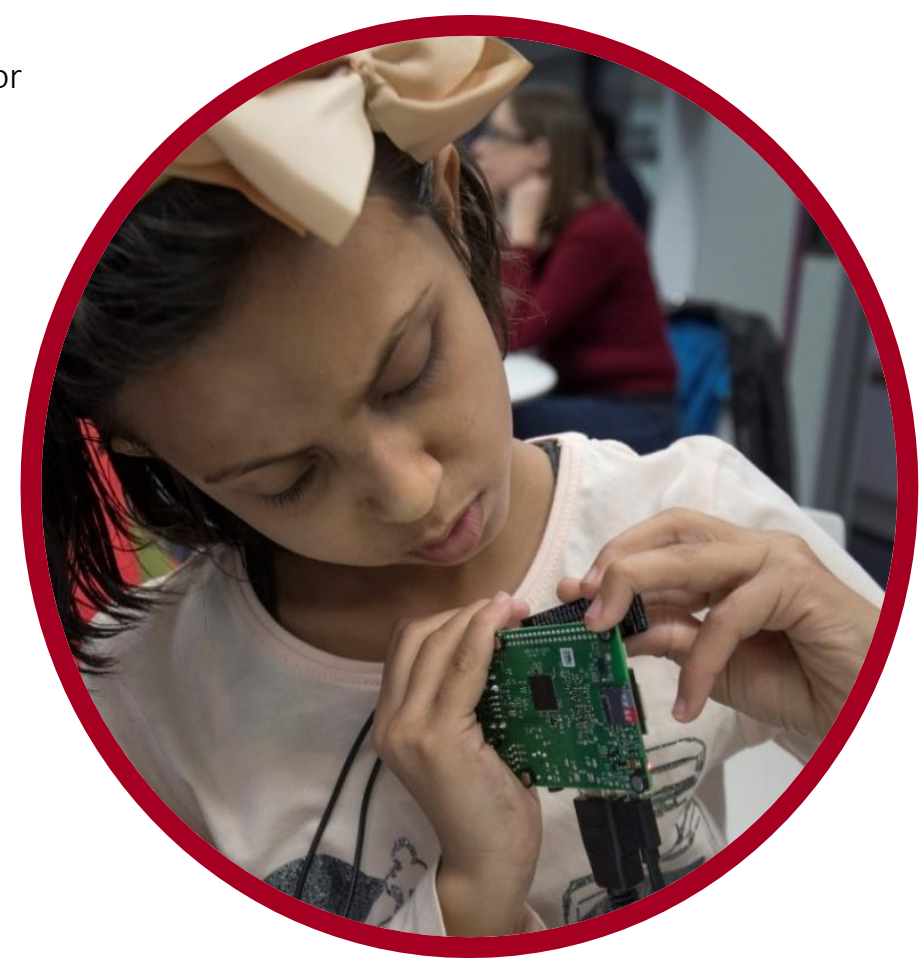


- Museums are engaging increasingly in evidence-based digital practice as data from web analytics and social media accounts are being reflected upon and used in decision-making processes.

See section 5

- Currently, there is little evidence that museums are systematically assessing and identifying digital skills needs. The need and strategic importance of doing some kind of skills needs assessment or analysis to identify in-house digital skills was recognised, but the challenge has been finding the time.

See section 5

- There is little evidence of in-house formal and planned training around digital skills or digital literacy. However, informal and ad hoc training to upskill and reskill staff and volunteers is being provided. Much development activity around digital is informal, with staff supporting each other and sharing skills.

See section 5

- There is evidence of an assumption in museums that 'digital skills' relate to a specific set of technical competencies. This can create a relationship with digital that is reactive, resulting in low digital literacy across the museum. However, importantly, there is also evidence showing that the museum sector has the potential and intention to adapt.

See section 6 


\section{Context}

\section{The notions of museum visit and museum object, collection and exhibition, have all been disrupted and renegotiated by the influence of five decades of digital technology. 'Digital' has changed the idiom of 'museum' (Parry, 2007; 2010).}

And yet, it is widely recognised that the digital literacy of the museum workforce remains one of the key challenges continuing to impede the adoption of technology within the sector (New Media Consortium (NMC), 2015; 2016). According to Nesta, the Arts and Humanities Research Council (AHRC) and Arts Council England (ACE) $(2014 ; 2015)$ and Nesta and ACE (2017), over a third of museums in England still feel that they do not have the in-house skills to meet their digital aspirations, and rather than improving, some digital skills areas have declined. Challengingly, the most recent findings, captured in the UK Government's Culture is Digital report, point to a cultural sector as a whole with 'particular skills gaps around intellectual property and data analysis' (Department for Digital, Culture, Media and Sport (DCMS), 2018). Addressing this pressing issue, the aim of the 'One by One' project is to leverage interdisciplinary scholarship, and specifically the concept of the 'postdigital museum', to understand how to deliver a transformative framework for museum workforce digital literacy.

Specifically, this research is investigating: the existing profile and reach of workforce digital development in UK museums; what new digital literacies are necessary for working in (or to become) a digitally mature museum in the UK today; and what the most appropriate 'activations' are, together with ways of supporting each of these digital literacies, within different museum settings - be that internally/externally, formal/informal, accredited/non-accredited, for individuals/teams.

Intellectually, the project harnesses an important recent shift in museological research around digital. A decade ago, the 'cultural turn' in digital heritage research was marked by a new theorising of the subject (Parry, 2005; Cameron \& Kenderdine, 2006). From 'visualisation' (Ch'ng, Gaffney, \& Chapman, 2013), to 'participation' (Kouper, 2016; Ridge, 2014), and

from mobile media (Tallon \& Walker, 2008), to social media (Charitonos, Blake, Scanlon, \& Jones, 2012; Drotner \& Schrøder, 2013; McKenzie \& Poole, 2011), few areas of digital media in museums have in this time eluded scholarly investigation. However, it is only more recently that another discourse ('the postdigital') has begun to offer an alternative conceptual framework in which museum studies research can engage with digital without defaulting to routine questions around technological 'innovation' and 'adoption' (Parry, 2013; Edmundson, 2015; Wellington \& Oliver, 2015; Kelly, 2016). The postdigital is allowing us to think about the museum after the digital revolution, where digital is managed normatively, and where digital pervasively becomes innate within a range of operations and definitions within the museum.

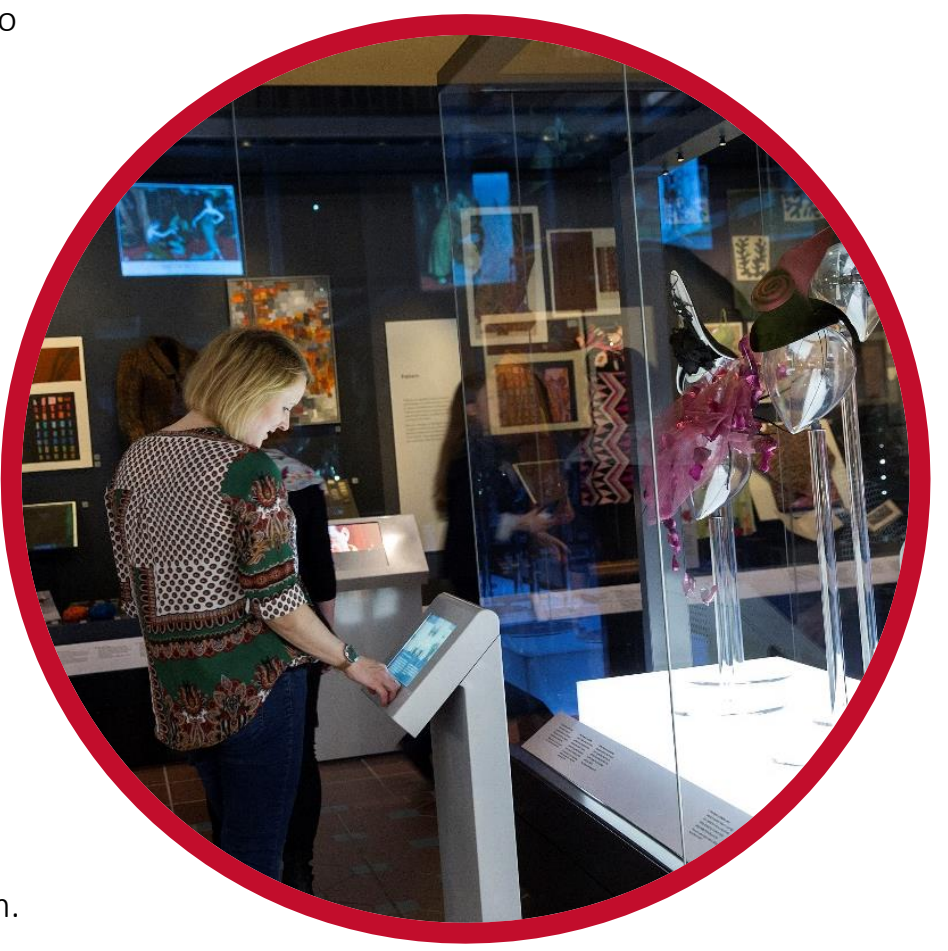


Using this progressive conceptual framework, the 'One by One' project aims to evidence the extent to which digital maturity is emerging within UK museums. In doing so, this project builds upon a body of scholarship that has focused on museum workforce skills and literacies. Importantly, this previous scholarship has shown that:

- Perceptions of the literacies required by professionals have changed over time (Marty, 2006: 331);

- With roles oriented towards information technology (IT), the museum sector can struggle to compete with other sectors (Davies, 2007);

- The creative industries sector skills gaps are intensifying in part due to the speed of digital change (Creative and Cultural Skills, 2011: 45; Howard, 2013);

- The interplay of skills and knowledge required for modern digital curatorship is complex (Jeonghyun, Warga, \& Moen, 2013); and

- Some modelling of these literacies and how they might be leveraged by the sector is possible (Baker, 2013).

However - as mostly surveys of existing provision - what this existing research has not attempted or investigated are substantive approaches to developing alternative and progressive approaches to digital literacy development within the museum sector. Addressing this methodological gap, the 'One by One' project is using humanities scholarship to design, empirically test and propose this alternative training and development provision.

This research also builds upon several years of a foundation study and international collaboration. In April 2014, higher education training providers from around the world met (at the Museums and the Web Conference 2014 (MW14)) to frame the 'Baltimore Principles', articulating the step changes needed for the next generation of digital training provision in the museum sector (NMC, 2016: 24). The 'Baltimore Principles' (a vivid example of postdigital thinking) were unequivocal in their call for a shift in the way we think about digital training in museums. They asked for a move from thinking about 'technical skills' around specific forms of technology, to thinking instead about 'digital literacies' and forms of creative (and design) thinking; a move from digital training being 'about technology', to being 'with technology'. They encouraged a switch in emphasis from 'reactive training' within an institution (where skills can become siloed), to 'strategic improvement and professional development' for the whole institution where literacies and ways of thinking and making can, instead, become pervasive and naturalised. And they challenged education providers to think about a training offer that was less didactic and more discursive; about an evolving collective expertise, rather than about a set of specific experts; outward looking, rather than inward looking; ongoing, and not time-bound; for everyone in the institution, not just an IT few. Working from these principles, the 'One by One' project aims to deliver a framework to support this step change within the museum sector.

This works also draws upon a series of action research projects that since 2010 have evidenced and formulated ways of planning, investing and collaborating on the development of the next generation of digital cultural activity (Finnis, Chan, \& Clements, 2011). Led by the non-profit, digital cultural publishing organisation Culture24, and involving museum and heritage institutions across the UK, the 'Let's Get Real' research programme has not only underscored the skills and knowledge gaps around digital within the sector, but has done so through a distributive community of practice. Leveraging this proven (action-based) approach, 'One by One' draws upon this existing evidence base and harnesses these established networks.

In short, 'One by One' offers a continued scrutiny of the concept of the 'postdigital museum', a further interrogation of the 'Baltimore Principles', and the proposition of an alternative workforce development framework. 


\section{Structure of the report}

The overall purpose of the report is to present evidence from the sector on how digital skills and literacies are understood, deployed, demanded, supplied and developed in order to provide an understanding of museums' digital maturity to inform the development of a transformative framework for museum workforce digital literacy. Following this introduction, section 2 outlines phase one of the 'One by One' project in terms of its objectives and the approach and methods adopted to examine the UK museums sector.

Section 3 provides findings of how digital is distributed in the UK museums studied in Phase One. Here, three models illustrate the patterns of digital engagement, how organisational structures and digital responsibilities are evolving, and what this means in practice for digital skills.

The concept of the skills ecosystem used to frame the findings of Phase One is presented in section 4. This section evidences how the ecosystem has developed and how it can be used to understand the skills ecosystem of the museum sector. Evidence from the literature is presented here to provide an overview of the current understanding of digital skills in the sector.

Section 5 then uses this framework to present evidence on how digital skills and, to an extent, digital literacies are being talked about in the museum sector. It draws on evidence from six case studies, the focus group with curatorial staff, plus interviews with representatives of small museums and the Museum Development Network. Challenges to the deployment, demand, supply and development of digital skills are outlined.

Section 6 discusses the key findings from Phase One focusing on the digital skills ecosystem of UK museums and how it can be adapted 


\section{Research methods}

\section{The first phase of the 'One by One' project ('Empathise') has mapped the landscape and thinking around digital skills and literacies in the UK museum sector through an empirical study (September 2017 to February 2018).}

The main objectives of this phase were:

- To map how digital skills are currently developed and supplied in the in the museum sector;

- To understand how digital skills are currently deployed in the museum sector; and

- To pinpoint the current changes in the demand for digital skills/literacy in the museum sector.

The findings of this phase provide an overview of current understanding and utilisation of digital skills and literacies, which will inform the proceeding project stages.

First, a desk-based review of the skills ecosystem for digital skills in the museum sector was undertaken. This systematic search of the extant literature focused on evidence on the museum sector workforce, skills needs and gaps, training and development and policy, primarily in the UK. The main focus was on the museum sector, but literature on the cultural and heritage sector more broadly was reviewed. A keyword search strategy was developed and refined, then used systematically across six electronic bibliographic databases (namely Business Source Complete; JSTOR; Ingenta; Scopus; Taylor and Francis; and Proquest). In addition, Google Scholar, specialist journals (namely Museum Management and Curatorship; International Journal of Heritage Studies; Museum and Society; Curator; Museum International; and Journal of Museum Education) and relevant websites (such as Arts Council, Museums and the Web conference website, Nesta, Creative and Cultural Skills, Association of Independent Museums (AIM), Museum Development Network and Department for Digital, Culture, Media and Sport) were also searched. Each stage of the review was documented, and the evidence managed in a bibliographic software programme. In total, 306 pieces of evidence were reviewed. Evidence to support our understanding of the skills ecosystem is included.

Second, primary research, using qualitative research methods, was undertaken to gain in-depth understanding of how digital skills are articulated, developed and used within the museum context through the actors involved and their interpretations. Six case studies of museums in England, Scotland and Wales were completed along with analysis of museum strategies and documentation, plus non-participant observation. Participating museums included: Amgueddfa Cymru National Museum Wales; National Museums Scotland; National Army Museum; Royal Pavilion and Museums Brighton and Hove; Derby Museums Trust; and the Museum of London. The research team visited each partner

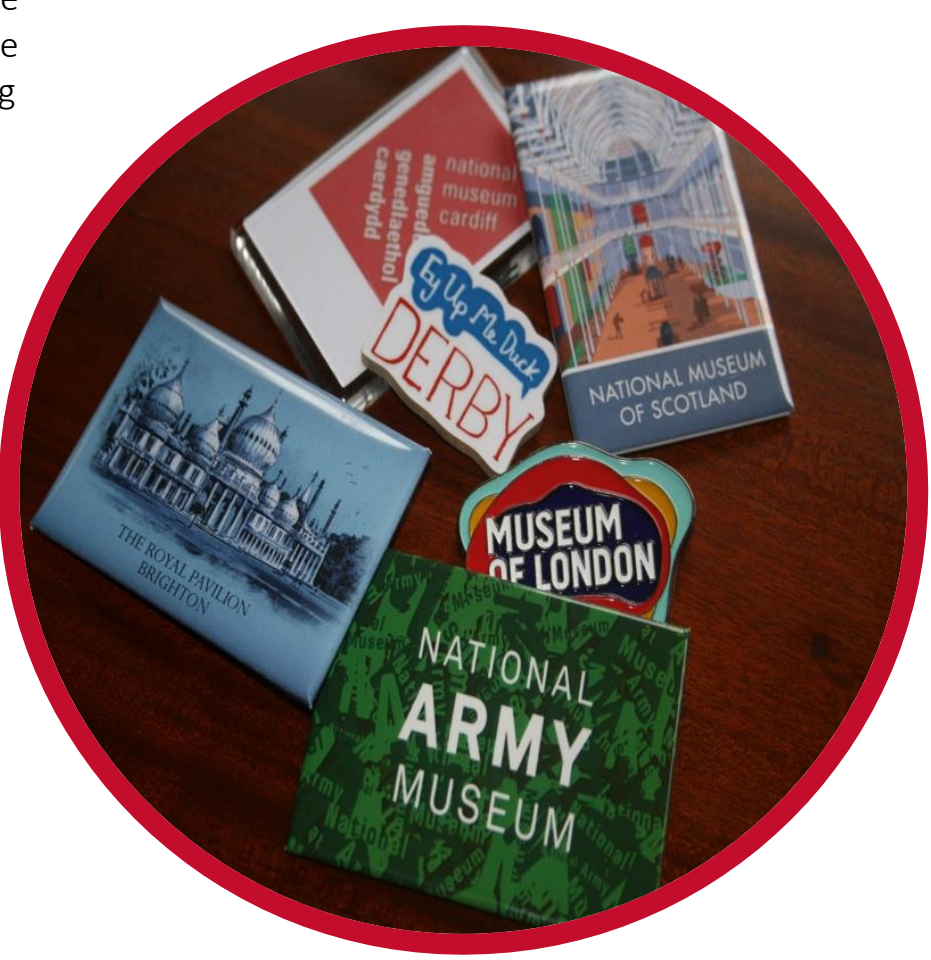


museum and conducted a total of 50 interviews with museum staff from all levels of the organisations, including representatives from management and staff from the following fields: training and development; curatorial; technician; communications and marketing; digital; and front of house. The interview schedules were informed by the findings of the literature review and included specific questions for managerial staff.

Additional interviews with AIM member museums were undertaken to get a better understanding of digital skills in smaller museums. Three interviews were conducted with representatives of small, independent museums to gain insights into the opportunities and challenges around digital skills and literacies that they face. A member of the Museum Development Network (MDN) with responsibility for supporting digital in small museums in one region was also interviewed.

When consent was given, interviews were digitally recorded and transcribed; otherwise the researchers took written notes. All of the research notes and transcripts were analysed using a matrix approach to compare and contrast material across the case studies allowing similarities and differences to emerge. The complexity of single museum case studies combined with the comparative analysis of multiple case studies produced in-depth insights into museums' skills ecosystems.

An online focus group (FG) with curatorial staff from the case study museums was also undertaken. Building on the review of the digital skills ecosystem and the case studies, the online focus group explored in-depth how curatorial staff have experienced the shift from digital skills to digital literacies, and the impact on their role. The online focus group discussion was captured and analysed using the thematic method: the transcript of the discussion was read and re-read until patterns and themes emerged.

Please note that evidence has been anonymised and where quotes from interviewees have been used generic job titles have been assigned 


\section{Models of digital in UK museums}

The implementation and application of digital technology has been supported and guided by the development of digital strategies, plans and policies led, in most instances, by museum management teams. Different practices in how digital responsibilities and skills are distributed, managed and/or shared have been identified across the case study museums.

Recent evidence describes and debates how digital departments in museums are structured and are becoming established in response to the digital age (James, 2015; Tallon, 2017; Stack, 2013). Cultural institutions have recognised that the digital shift is changing the delivery of their work, and with it the formation or reconfiguration of their digital departments (Tallon, 2017). These departments were seen to have digital expertise and responsibility for the digital functions and activities within their institution. As a consequence, digital is often centralised within an organisation. Critics of this model suggest that the delivery of digital activities and programs needs to be shared and collaborative (Stack, 2013). They regard a single department responsible for digital as unsustainable, particularly in medium-sized and large organisations (James, 2015), and advocate a 'broader institutional approach' (Tallon, 2017). Tallon (2017) suggests that the variance between digital departments in museums in the USA can be explained by differences that already existed when digital departments were originally established and then restructured. These differences might relate to strategic vision, funding, human resources issues, middle-management tensions, leadership preferences, or the recommendations of external consultants. Across the case study museums, evidence of these differences is recognised.

The following three models (centralised, hub and spoke, distributive) illustrate how digital responsibilities and activities are variously distributed in the case study museums. They exemplify the patterns of digital engagement, how organisational structures and digital responsibilities are evolving, and what this means in practice for digital skills. For each model, the person who has responsibility for digital is defined, together with: descriptions of digital practice; the type of organisation the digital model is likely to be found in; whether digital activity is planned, responsive and/or ad hoc; what this means for digital skills development; and the challenges and benefits of the model in terms of digital. It is important to note that these models do not suggest one model is better or that it is a progression to digital maturity. These models are shaped by a number of factors including organisational structure, resources (both in terms of

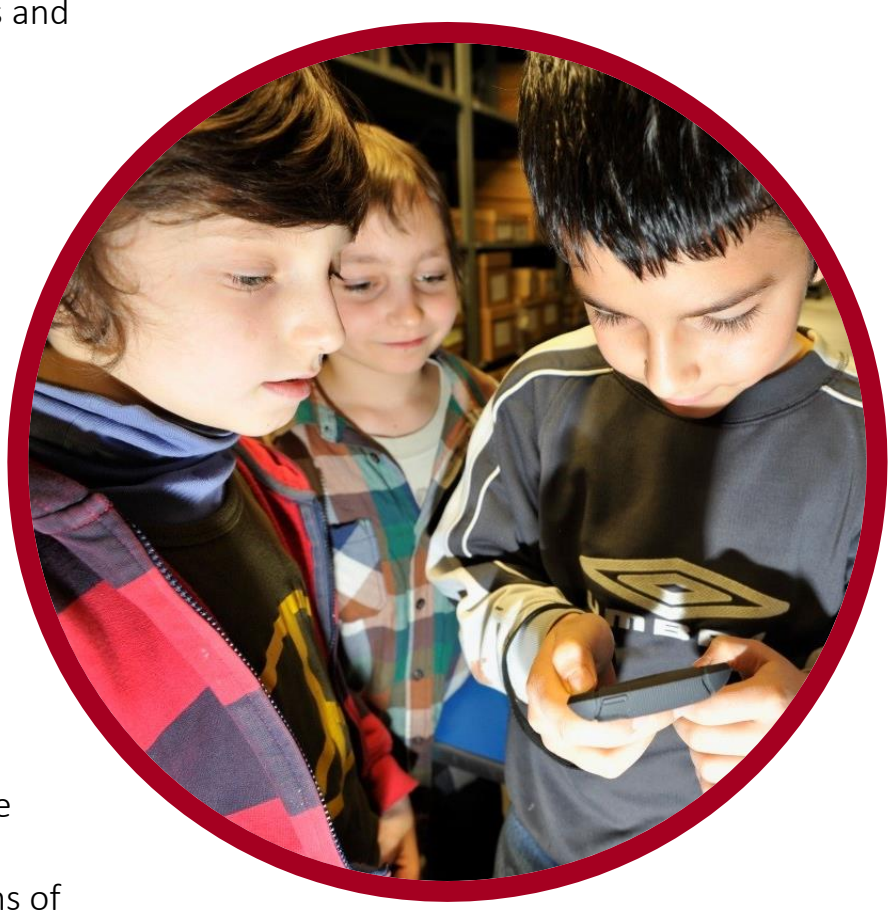
personnel and finances), organisation mission and strategy 
Table 1 Models of digital distribution across UK museums

\begin{tabular}{|c|c|c|}
\hline Centralised digital model & Hub \& Spoke digital model & Distributive digital model \\
\hline \multicolumn{3}{|l|}{ Who } \\
\hline $\begin{array}{l}\text { The museum has a team or } \\
\text { department (such as a marketing } \\
\text { and communications team, digital } \\
\text { team) that takes responsibility for } \\
\text { digital activity, planning and } \\
\text { strategy. }\end{array}$ & $\begin{array}{l}\text { A core team oversees the digital } \\
\text { activity, strategy and planning, but it } \\
\text { supports and encourages others to } \\
\text { engage in digital. }\end{array}$ & $\begin{array}{l}\text { The museum does not necessarily } \\
\text { have a core digital team, but rather } \\
\text { 'digital' people are embedded within } \\
\text { teams and departments across the } \\
\text { museum with the aim to distribute } \\
\text { digital across the workforce. }\end{array}$ \\
\hline \multicolumn{3}{|l|}{ How } \\
\hline $\begin{array}{l}\text { There are clearly defined practices } \\
\text { for doing digital and those } \\
\text { undertaking the work have clearly } \\
\text { defined roles. }\end{array}$ & $\begin{array}{l}\text { Digital provision is overseen and } \\
\text { undertaken by a few, but others will } \\
\text { be supported and encouraged to do } \\
\text { digital. }\end{array}$ & $\begin{array}{l}\text { Digital provision is overseen by a few } \\
\text { across the organisation, but the } \\
\text { responsibility for digital is shared. } \\
\text { The digital 'vision' is shared. Digital } \\
\text { strategies are developed } \\
\text { collaboratively, with all invested. }\end{array}$ \\
\hline \multicolumn{3}{|l|}{ Where } \\
\hline $\begin{array}{l}\text { Larger, structured organisations, } \\
\text { perhaps hierarchical, where staff } \\
\text { have clearly defined roles and } \\
\text { responsibilities. Digital strategies are } \\
\text { developed by management to guide } \\
\text { digital activity. }\end{array}$ & $\begin{array}{l}\text { Smaller museums or those operating } \\
\text { as a number of sites where staff } \\
\text { have a number of roles and } \\
\text { responsibilities. }\end{array}$ & $\begin{array}{l}\text { Holacratic organisations, project- } \\
\text { based team-working where } \\
\text { decision-making is distributed and } \\
\text { roles are less well defined. }\end{array}$ \\
\hline \multicolumn{3}{|l|}{ What } \\
\hline $\begin{array}{l}\text { Digital activity is planned and } \\
\text { managed. }\end{array}$ & $\begin{array}{l}\text { Digital activity and engagement is } \\
\text { both planned and responsive. }\end{array}$ & $\begin{array}{l}\text { Digital activity and engagement is } \\
\text { responsive, with a sense of proactive } \\
\text { engagement. }\end{array}$ \\
\hline \multicolumn{3}{|l|}{ Skills } \\
\hline $\begin{array}{l}\text { Skills are centralised; it is difficult to } \\
\text { build digital literacies and to instil } \\
\text { confidence in others. }\end{array}$ & $\begin{array}{l}\text { Skills are located in the hub and } \\
\text { across spokes; skills are shared and } \\
\text { there is potential to build on } \\
\text { individual digital literacies and to } \\
\text { instil confidence. }\end{array}$ & $\begin{array}{l}\text { Skills are shared; individual digital } \\
\text { literacies are built upon, instilling } \\
\text { confidence in others. }\end{array}$ \\
\hline \multicolumn{3}{|l|}{ Benefits } \\
\hline $\begin{array}{l}\text { Digital activity is co-ordinated and } \\
\text { consistent. }\end{array}$ & $\begin{array}{l}\text { Digital skills can be developed easily } \\
\text { as a sense of shared digital learning, } \\
\text { test and learn ethos accepted. }\end{array}$ & $\begin{array}{l}\text { When fully distributed, there is a } \\
\text { strong learning culture, easily able } \\
\text { to develop digital literacy amongst } \\
\text { workforce. }\end{array}$ \\
\hline \multicolumn{3}{|l|}{ Challenges } \\
\hline $\begin{array}{l}\text { There is a lack of innovation and } \\
\text { creativity, a slowness to adopt } \\
\text { digital, and digital is not integral to } \\
\text { thinking. }\end{array}$ & $\begin{array}{l}\text { There is a need to have digitally } \\
\text { confident people in place, and a } \\
\text { need to allow people to test and } \\
\text { learn. }\end{array}$ & $\begin{array}{l}\text { There is a need to have a shared } \\
\text { understanding across organisation, } \\
\text { clear strategy, where not fully } \\
\text { distributed then at risk of } \\
\text { learning/ideas not shared. }\end{array}$ \\
\hline
\end{tabular}




\title{
4 Understanding a museum's digital skills ecosystem
}

\author{
This section provides an overview of the concept of the skills ecosystem, how this \\ concept has developed and how it can be used to understand the skills ecosystem of \\ the museum sector.
}

\section{Conceptualising a 'skills ecosystem'}

Informed by employment studies scholarship, this initial phase of research conceptualises museum digital skills as an 'ecosystem'. The concept of the skills ecosystem was developed by Finegold (1999) to distinguish between high-skill ecosystems (defined as having competitive advantage, high wages and strong capacity for innovation) and low-skill ecosystems (defined as having low productivity, low wages and a low value-added business strategy). It was later developed by others (such as Anderson \& Warhurst, 2012; Buchanan et al., 2001), to provide a framework in which to understand the context and conditions of skills deployment, demand, supply and development within a specific setting - an organisation, a sector or a national economy. Recent research highlights the importance of understanding the context of skills and recognising that a range of mechanisms are at play within an ecosystem (Buchanan, Anderson, \& Power, 2017). The four elements (of skills deployment, demand, supply and development) have been found to be common across what were defined as self-sustaining skills ecosystems (Anderson \& Warhurst, 2012; Buchanan et al., 2001; Finegold, 1999). Self-sustaining skills ecosystems 'generate positive, mutually reinforcing dynamic[s] that fuels ongoing knowledge creation and growth and adaption to changing competitive conditions' (Finegold, 1999: 61). The skills ecosystem is, therefore, today a widely used concept to understand how skills are utilised and can be adapted to changing labour markets and work conditions.

This 'skills ecosystem' concept was developed as a way to move beyond the commonly used 'supply and demand' model of skills, in order to take account of wider and more complex educational, economic and political contexts that can impact on skills within a given context. Critically, it is factors such as business setting, structure of jobs, work organisation and training that are linked within this framework to understand the development and deployment of skills (Buchanan, Anderson, \& Power, 2017; Buchanan et al., 2001; Finegold, 1999; Windsor \& Alcorso, 2008). Within skill ecosystems, it is recognised that advanced and specialist skills are deployed and developed through a range of mechanisms such as workforce development strategies, structure of jobs, innovative work

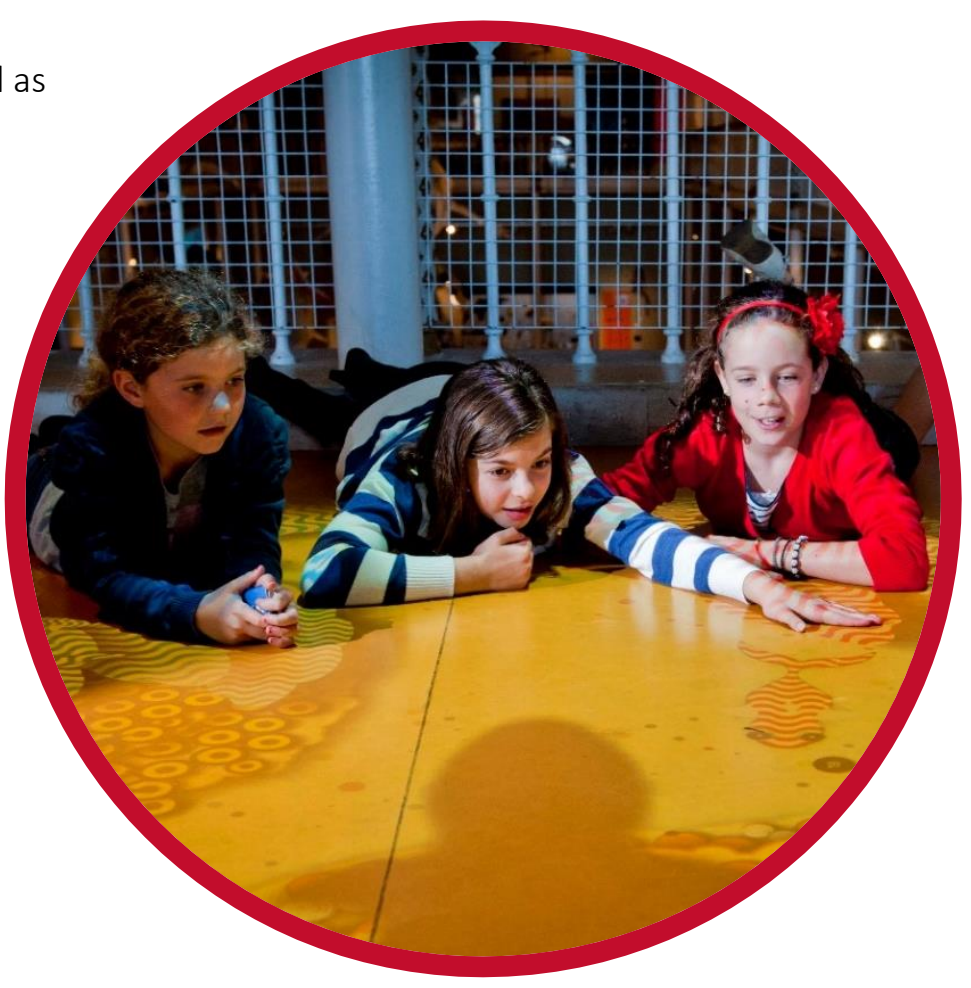


environments and career progression (Buchanan, Anderson, \& Power, 2017; Finegold, 1999). Recent international evidence suggests that within national and local contexts, a skills ecosystem can be changed to improve skills utilisation and employability, combat unemployment, meet skills needs, and support profitability and growth (OECD/ILO, 2017). Consequently, for considerations of museum digital skills (and for the 'One by One' research in particular), the concept of skills ecosystems provides a framework within which to explore and question how, where and why skills are developed, utilised and sustained within an organisation or sector.

\section{Understanding the skills ecosystem in the context of the museum sector}

The skills ecosystem is defined by four interdependencies: deployment; demand; supply; and development.

Deployment defines how skills are utilised and effectively practised within the context. Ecosystems benefit when the skills, expertise and knowledge of the workforce are utilised well (Anderson \& Warhurst, 2012). Utilisation can be about changing job roles and structures to facilitate multi-skilling. It is intrinsically linked to skill development. Skills deployment can also be seen where roles have evolved and expanded in response to sector demands, organisational change, technological developments and, in some instances, professional development. In the museum sector, there was evidence that individual roles have expanded to include digital responsibilities. For instance, traditional audio-visual (AV) roles have changed to include the installation and maintenance of more complex digital interactives. There is much discussion in the literature on how curatorial roles have expanded to include the production of digital content, engagement in social media, curation of digital-born objects and digital preservation. So, there is extensive evidence on how and what digital skills and competencies are being deployed across curatorial and other museum roles; for example:

- Social media skills (Garibaldi, 2015; Lopez et al., 2010; Proctor, 2010; Pedro, 2010; Suzić, Karliček, \& Stříteský, 2016);

- Knowledge of social tagging (Cho et al., 2012; Owens, 2013);

- Manipulation of digital images (Redman, 2007; Schroer, 2012);

- Blogging (Verboom \& Arora, 2013);

- Understanding of Intellectual Property Rights (IPR) (Tsolis et al., 2011);

- Designing and using 3D technology (Liritzis et al., 2015; Younan, 2015); and

- Designing and using virtual and augmented reality (Donghui et al., 2017; Yoon et al., 2012).

However, there is little evidence on how digital literacies are being deployed in the museum sector. Evidence from the heritage sector emphasises the importance of digital literacy from the sector and audience/consumers in order to innovate (Borowiecki \& Navarrete, 2017).

Demand is concerned with recognising what skills are needed in the ecosystem and what may be needed in the future to address the changing context. Demand is sometimes seen as playing a role in driving change and stimulating innovation and development within an ecosystem (Buchanan et al., 2001). Within an ecosystem, it is recognised that recruitment can often not meet the skill demands of the system (Finegold, 1999); these missing skills can be generic, transferable and/or specialised. So, within the museum sector, the drive to digital is inevitably demanding specialised skills, expertise and knowledge in order to, for example, manage and catalogue collections, to shape exhibitions, to disseminate knowledge and to engage current and new audiences.

Current evidence on skills demand in the museum sector can be derived from literature on an analysis of job descriptions, which provides a clear indication of a growing demand for digital. There is a shift 
in job descriptions for 'museum professionals' where it is evident that there are demands for new competencies and mindsets (Jeonghyun, Warga, \& Moen, 2013; Matos \& Carvalho, 2016; Visser, 2013; White, 2016). This shift is seen as a result of technology and the drive to digital. An analysis of job descriptions for curators in the US library and museum sector highlighted the interplay between professional knowledge, technical skills (such as understanding software, web mark-up languages, relational databases, digital repositories) and digital knowledge (understanding metadata) (Jeonghyun, Warga, \& Moen, 2013). It was evident that educational background and professional experience were prioritised in advertisements over digital curation skills, but that 'digital' was still a prominent feature of job advertisements.

Evidence on skills demand can also be understood in terms of how roles are changing in the sector. The curatorial role is recognised within the literature as having experienced the most significant change as a result of the shift to digital (Li, Liew, \& Su, 2012; Madrid, 2013; Melting Pro, 2017; Tammaro \& Madrid, 2013; Tibbo, 2010; Tibbo \& Lee, 2012a, 2012b). Tammaro and Madrid (2013) identified both operational (such as selecting and appraising digital objects and digital-born objects, understanding structure of digital objects and their storage/preservation, being aware of data provenance) and management competencies (such as implementing and monitoring digital curation projects, understanding the risk of data loss, managing metadata standards) required for digital curators in the future. Others note that those involved in the education programmes and learning spaces provided by libraries and museums also require a range of digital competencies (Koh \& Abbas, 2015; Moore, 2015). The demand for new competencies (such as programme development and the facilitation of learning) was noted to have implications for how the curriculum in the sector may need to be redesigned to emphasise teaching and learning with technology (Koh \& Abbas, 2015).

Supply is considered to be the 'nourishment' of the system (Finegold, 1999). There is an emphasis on recruitment: extending skills, expertise and knowledge through new staff. Recruitment to an organisation or a sector, however, is associated with its ability to attract those with the right (or demanded) skills, expertise, knowledge and/or qualifications by offering salaries commensurate with the same roles in other sectors. However, evidence on positive ecosystems highlights the multidimensional element of the system with a need to address all sides of skills (Windsor \& Alcorso, 2008). Supply is, therefore, also about career development pathways and strategies that focus on retention.

There is some evidence on how new skills and competencies associated with digital are being supplied to the sector. For instance, Hutchison and Cartmell (2016) report on a successful programme of internships in Museums Galleries Scotland. Individual internships were developed around skills shortages in specialist areas; digital skills was one such area. The internships comprised a bespoke training programme, networking and mentoring. This internship programme was considered an effective method by which to supply skills needed into the sector.

Controversially others posit that the professional qualifications of those working in the galleries, libraries, archives and museums sector will become less important with greater integration of technology (Shipp, 2016). It is suggested that the workforce will need to be multi-skilled and multidisciplinary in order to be able to adapt to technological innovations and challenges.

Development is focused on how skills, competencies and expertise are nurtured within a context and, importantly, goes beyond training interventions. Skills development can be part of formal learning, inhouse or on-the-job training, or informal learning. As suggested by some, skills development within an ecosystem can be effective where experimentation is fostered and supported (Buchanan et al., 2001). Within the museum context, where the workforce is encouraged and supported in their use of technology, skills can be developed. This, in the medium term, leads to a more digitally confident and/or a digitally literate workforce.

There are a number of examples across the museum sector and more broadly in the library and galleries sectors of how digital skills and competencies are being developed (Fulton, Botticelli, \& 
Bradley, 2011; Goss, 2016; Ray, 2017; Welsh, 2013). From the US, a graduate program in digital information management was developed to support digital curation in the museum and library sector (Fulton, Botticelli, \& Bradley, 2011). The blended learning curriculum consisted of practice in digital technology, understanding of interdisciplinary management and policy development with a purposebuilt digital laboratory. As a professional development course for those with a museum or library professional qualification, it was considered successful in developing both hard and soft skills necessary to engage with digital in the professional context. It was also found to fit with career goals of those entering the museum and library sector and considered a beneficial addition to their main qualification.

More recent evidence from the US supports the finding that digital skills should be embedded within the museum studies curriculum, as they are currently developed on the job (Ray, 2017). Whilst it is an accepted valid career path in the sector, Ray (2017) noted that it is important to have shared understanding of the practice of digital and that it is integrated into the curriculum so that the sector can advance and innovate.

Evidence from Australia examined the development of digital capabilities across the galleries, libraries, archive and museums sector noting that much could be learnt and shared from across the fields (Goss, 2016). For archivists, it was noted that both soft and technical skills are needed to develop digital capability. Interestingly, evidence suggests that the digital maturity of the organisation could be a factor in the development of digital skills and competencies.

The review reveals that whilst there is evidence, both from the UK and internationally, on the impact of digital on the deployment, demand, supply and development of skills, competencies and capabilities from the cultural sector, there is little research on digital literacies. This highlights a gap in our understanding. The review provides an initial understanding of what is already known about digital skills in the museum sector mapping to the skills ecosystem framework, but evidence presented next contributes to and extends this understanding. It provides a foundation on which to explore how digital skills and literacies can be developed, supported and maintained in the longer term 


\section{Understanding digital skills in the UK museums sector}

This section explores the empirical evidence on digital skills and digital literacies in the museum sector. Guided by the skills ecosystem framework, it discusses the deployment, demand, supply and development of digital skills, or in other words: How and where are digital skills put to work? What digital skills are needed and who provides them? How are digital skills developed? What are the challenges to effective digital skills ecosystems in the museums sector?

These questions are, of course, interdependent: for instance, how skills are deployed is influenced by what skills can be supplied and developed. Complexities such as these were clearly evident in the six case studies, the focus group with curatorial staff and the interviews with representatives of small museums and the Museum Development Network conducted for 'One by One'. This report, however, does deliberately not retrace all these complex interdependencies. Instead, with the aim to provide starting points for better understanding and practice, this section cuts through complexities and focuses on key findings from the empirical research.

\section{Deployment of digital skills}

Within the skills ecosystem approach, deployment looks at how skills are applied in a specific context: how are skills put to work, what for and by whom? What are the different roles in which skills are used, and how do the structures around those roles - the organisation of work, for instance, or the tasks of a project - influence skill deployment? This section explores how digital skills are deployed in museums, focusing on:

- Exemplar projects deploying digital skills and competencies;

- Specialist digital roles; and

- Digital in generic roles and skillsets.

Exemplar projects deploying digital skills and competencies

In all case study museums, digital skills and competencies are being deployed across a range of museum projects, and have been for some time. More recently the deployment of digital skills centres on key projects that, across the museums studied, stood out as current focal points of digital activities and that involve collaborations between departments across museums.

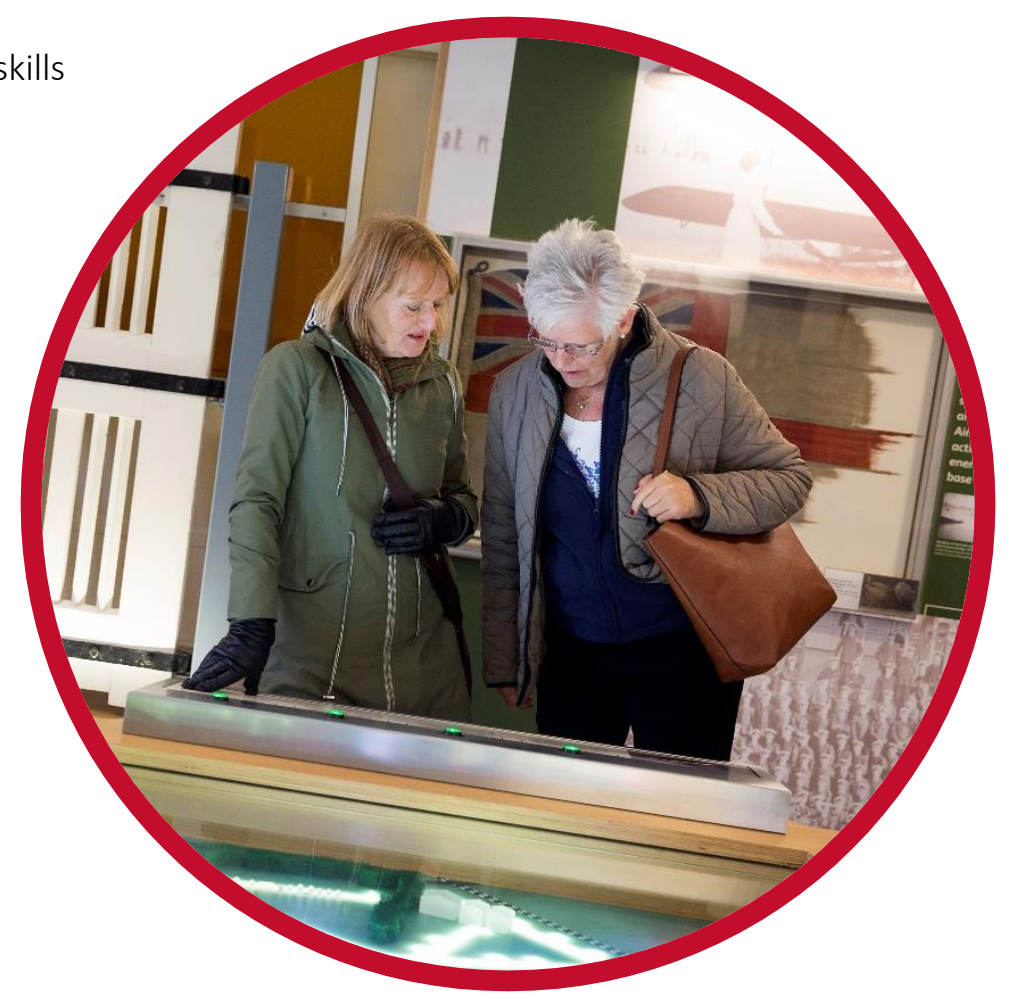


First, all of the case study museums (plus some of the small museums) had recently redeveloped their websites. These redevelopments tended to double up as an opportunity to think strategically about 'digital' and to consult staff and audiences about web presence. A museum's website was often viewed as another important museum 'site', whether as an extension to the museum's physical galleries or a 'site' in its own right, for instance for research and content co-creation. For all of the small museums, too, websites are vitally important and 'something you have to keep working on as well as constantly update the content' (Small museum representative 1). The website redevelopments required the deployment of a range of technical and digital skills, which made museums realise that they needed to develop these skills first, and would need to continue developing skills for similar projects in the future. One small museum representative (3) recognised that whilst recruiting for a web manager, they would also need a digital content manager to support the role.

Second, a major undertaking in all case study (CS) museums is the ongoing digitisation of collections. There are a number of drivers to digitisation, but enabling greater access to collections is considered its major benefit. Digitisation can make items accessible, at all or in new ways, for instance for learning purposes:

There was a scrapbook of this particular suffragette, a local lady. And the scrapbook itself was in such a fragile state [...] we wanted to use it for an educational resource, schools resource, and we wouldn't have been able to allow close contact with that item. [...] So, I digitised all of the pages of the scrapbook, and now they're on a tablet, or a couple of tablets, for schools and children to look through and research. (Curator, CS2)

The case study museums also deploy digital skills for making digital collections available online, hosted on their own website or on social media, and for creating content as part of that online presentation. Examples include:

- Amgueddfa Cymru - National Museum Wales, https://museum.wales/collections/;

- Derby Museums, http://dmnature.tumblr.com;

- Museum of London, https://www.instagram.com/museumoflondon/;

- National Army Museum, https://collection.nam.ac.uk;

- National Museums Scotland, https://www.nms.ac.uk/explore-our-collections/; and

- Royal Pavilion and Museums Brighton and Hove, https://brightonmuseums.org.uk/discover/collections/.

The digitisation of collections is important not only as an example of how digital skills are being deployed within the sector, but also because it requires comprehensive efforts to digitally upskill the museums sector workforce. The ability to photograph and scan, manipulate images and use online catalogues and database systems is key to digitisation, but the breadth and depth with which these types of skills were required did not, and still does not, map easily onto the skills supply in the sector (see below).

A third and prominent example of digital skill deployment is in the development of innovative digital outputs. All case study museums engage in activities such as developing digital education and learning resources or producing digital replica objects and digital re-presentation of objects. These digital outputs are providing new ways for engaging audiences (such as geo-mapping, Periscope), for presenting objects and facilitating interaction with objects in the museum (such as 3D scanning and printing). For these applications to be effective, though, digital skills, knowledge and preferences on the part of the audiences also need to be taken into account:

Research is done into making sure that the apps that are being used by, say, children, families, [are] apps that they are familiar with. So, they will come to the museum and they will work with 
something that they recognise, and they know how to work [...] So, we did a big project on Minecraft, which is [a] really popular and successful game. (Digital learning manager, CS5)

As with the digitisation of collections, developing innovative outputs emphasises a strong link between the deployment of existing digital skills (to deliver current innovations) and the need to maintain and enhance the digital skills supply (to ensure the capacity to deliver innovations in the future).

Opinions on the role of social media varied, as did debates on how social media skills should be deployed and by whom. Several museum social media accounts exist, which were all linked to projects and operated by staff on project teams. In one case study museum (CS4), social media was an integral part of their engagement strategy and its use was distributed. A member of the marketing team oversaw communication and supported project teams. Staff also used their personal social media accounts to promote the museum and its work:

We allow staff to have their own account and they can mention the museum and they can do what they like. And we trust people. [...] Social media is about being social. [...] It's about working with people in a friendly way, and that means it's useful for people to know who we are and believe that we're people. (Senior manager, CS4)

In another case study museum (CS2), staff deployed communication skills on Twitter. However, Twitter was also seen as a declining medium and was not always considered the appropriate tool to reach museum audiences and promote events. Museums variously used Facebook to interact with local community groups and Snapchat to engage younger audiences. For small museums in particular, social media (including Twitter, Instagram and Facebook) could provide low-budget options to overcoming resource constraints. After consulting with specialists at other museums, one small museum decided to use Flickr to overcome the limitations of their collection management system and ensure that their photographic collection was easily accessible to the public and search engines:

It's a priority for us to get our photographs online. [...] We started using Flickr and it's still ongoing. It allows you to tag and index the images which is incredibly useful. [...] It is easy to use and it allows you to get the metadata there easily. Flickr also drives traffic internally, it acts as a search engine for you, and the cost of using it is quite minimal. (Small museum representative 2)

Notably, most curators in the focus group talked about contributing to their museum's social media presence and the need to understand this communication channel and how best to use it, emphasising another area of digital skills deployment.

\section{Specialist digital roles}

The above are illustrations of what digital skills are being deployed on. The ways in which digital skills are deployed are considered next. Across all museums, key digital skills were being deployed through dedicated digital roles, such as:

- Digital content creators - responsible for digital experience and content and user analysis; creating and updating formal policies and guidance around the use of social media.

- Digital programme staff - responsible for managing digital projects (e.g. a new website) and supporting digital elements within other projects; establishing best practice for including digital elements in all projects and working productively with the digital team.

- Digital learning staff - responsible for creating and managing online learning resources; creating digital learning content for educational activities and school visits.

- Digital curators - specialising in resourcing, collecting and exhibiting digital-born material.

- Digital collections staff - responsible for adding data into and managing museum collection management systems. 
- Digital developers - responsible for designing, testing and delivering software; web content management; commissioning user testing; optimising web content; managing digital infrastructure and storage.

How many such specialist digital roles exist in a museum, and how they relate to other, non-specialist departments and projects, depends on a museum's size as well as its digital model (section 3). All case study museums had at least some of the above roles in-house. In newly created roles interviewees were often able to develop and shape the digital element of the role and use opportunities to learn new skills. Again, but across all museums, deployment of some digital skills was also in the form of a bought-in resource (see Supply of digital skills below).

In small museums the deployment of specialist digital skills is organised differently. Staff are less specialised than in larger organisations, but more importantly, because smaller museums have a less broad resource pool overall, there are often no roles that are wholly dedicated to digital activity:

Small museums [...] might have a learning programme manager [...] but in many cases, it's one or two people who do everything. And having a job that's specifically focused on digital, compared to having a general museum job, where you do digital tasks, are two very different things [...] they don't have the time to commit to digital activities. (MDN representative)

Moreover, in small museums digital tasks that might otherwise be split into several digital roles are undertaken within the same role, and typically in addition to other, non-digital tasks. One representative of a small museum, for instance, described being responsible for creating the digital strategy (with support from the Board of Trustees); commissioning the museum's new website and working with the developer; and regularly updating the website. While roles combining the deployment of such broader ranges of digital skills can be challenging, there were many examples of small museums successfully engaging in digital activity, completing digital projects and gaining Accreditation status as a result.

\section{Digital in generic roles and skillsets}

Across all of the museums (both the case study museums and some small museums), interviewees also described a range of generic skills and competencies that they deploy in their role, including:

- Domain-dependent skills - specialist skills (select, collect, organise, interpret, conserve, present, re-present) and knowledge specific to museology or the role within the museum;

- Generic skills - communication, management, information processing, team working, research, planning, interpersonal, presentation, creativity, design;

- Technical skills - email, word processing, spreadsheets, presentation software, basic html, file transfer protocol (FTP), JavaScript (and other programming languages), web design, web publishing, running websites, app development, database management, photography, 3D scanning, 3D modelling software, photo editing software, open source software, file sharing software, time lapse camera use, work with analytical equipment such as X-ray fluorescence;

- Digital skills - management and manipulation of digital and moving images, ability to understand web analytics and social media data, writing online content, assessing and managing online information, online communication, photogrammetry, live streaming, use of different operating systems;

- Specific digital skills - blogging, CMS Mimsy XG, Adlib, Facebook, Instagram, Tumblr, Twitter, MailChimp, 3D image sharing websites (Sketchpad, Sketchup), design programmes (InDesign), Periscope, Raspberry Pi, Spotify, Photoshop, Audience Finder, Inkscape, Adobe Creative Suite, Dropbox, Event Brite, WordPress, Snapchat, Curo 3D, CAD/CAM, Google+, Hootesuite, Buffer, TweetDeck. 
Many of these skills either have a digital component (e.g. organising collections or planning) or can be understood as wholly digital, and interviewees talked about digital skills and competencies becoming 'core' to the diverse ways of working:

Focus[ing] on digital competency [...] and making that core to our way of working as a kind of key professional skill alongside the plethora of other professional skills [...] I think, has been one of the fundamental shifts that we've made. (Senior manager, CS6)

As with the specialist digital skills, the density and extent of digital skills development in generic rolls varies with a museum's overall digital model. But a minimum of digital skills, even if pertaining to general operations or information technology rather than museum-specific activities, appears to be deployed in every role.

\section{Demand for digital skills}

The deployment of digital skills is closely linked to questions of demand: What skills are needed in the current context? What may be needed in the future to address any changes in context? The case studies showed that digital aspects have grown across roles in all museums, requiring both more generic and specialised digital skills. The drive to digital is demanding specialised skills, expertise and knowledge in order to, for example, manage and catalogue collections, shape exhibitions, disseminate knowledge and engage current and new audiences. Across a number of museums, the drive to digital was also stimulating innovation and creativity, prompting museums to explore, learn and demand skills that they may not have considered otherwise. This section explores the demand for digital skills across the museums studied, focused on:

- Drivers of demand for digital skills;

- Role changes and the demand for digital skills;

- Digital understanding and digital literacy demands;

- Digital skill demands in small museums; and

- Future skills demands.

\section{Drivers of demand for digital skills}

The demand for digital skills is driven by several factors, most prominently: funding requirements; audience and stakeholder expectations; sector competition; and expanding the work of the museum. Exploring these drivers improves our understanding of what shapes skills demand in the sector and how that demand may shift.

The first and most concrete driver of digital skills demand is the recent creation and online publication of digital collection catalogues. This digitisation is partly undertaken to meet funding requirements or to simply keep up with sector standards. But there is also a genuine commitment to, and desire for, making information available more broadly and through a greater variety of channels. One case study museum (CS4) sees the creation of digital content as so integral to their work that they try to include digitisation budgets in all their bids for funding, aiming to secure as much resource as possible for cataloguing objects in the collections management system, digital photography and images, 3D scanning and digital recordings. Small museums can find it challenging to convincingly articulate digital in funding bids because of a lack of skills or inadequacy of the existing technology:

The old [online] catalogue was archaic. I couldn't use it very well, but in the end the software was not supported any longer, and we were backed into a corner. We commissioned a person who did a very sensible technical job. We've made a thematic catalogue and we are looking into ways to [...] refine it and now we want to do more. (Small museum representative 1) 
A second driver of digital skills demands is the growing expectation of digital formats, communications, experiences and services amongst audiences, stakeholders and the museums workforce. In the case studies as well as small museums, digital was regarded as 'something that is so integral to everyday life that it seems, it would seem strange if museums weren't doing it' (Curator A, CS4). Because '[digital] is happening' (Senior HR (human resources) manager, CS3), museums need to have an online presence and enable relationships with visitors before, during and after their visit. Visitors expect information to be readily available and online:

I think meeting the expectations of our visitors and stakeholders, well, various stakeholders, but our visitors and users of our collections. That's a massive driver. And just improving access to collections and adding context to objects, stories, galleries. (Curator, CS2)

Depending on a museum's brief, engaging and interacting with geographically remote or disabled audiences that may not have the opportunity to visit the museum physically can be a specific 'duty' (CS3, Small museum representative 3). Importantly, museums' digital work is driven not only by visitors, but generally by more people communicating, researching and searching online, and using museums as sources of authoritative information.

A third driver of digital change, and thus digital skills demand, is competition from within the sector, or 'fear of missing out':

People are terrified that if they're not on the digital train, we will miss opportunities and we'll be behind the times and we'll be that museum that didn't quite, you know, get with it and no one will come to us anymore. (Training and development manager, CS3)

Some interviewees compared their museum with other museums and institutions in the cultural heritage sector, and recognised that their own institutions could and should be doing more in terms of digital. Their view was that digital tools, technology and products are available and should be taken advantage of. But although fear of missing out clearly drove digital thinking and skills demand, there was also, in parallel, and more than a sense of competition, rather a cautious approach, a standing back and seeing what others did, and being circumspect about investing (both financially and in terms of upskilling the workforce) in new technology.

Finally, but possibly most fundamentally, demand for digital skills is driven by the aim to generally expand and improve what museums do, from working with digital-born objects to engaging and interacting with physical and online visitors, to becoming providers of online learning resources. For instance, a marketing manager talked about the possibilities for linked-up and shared collections:

[digital technology] just opens up to any number of possibilities of how you can extend reach to the collection, make it work harder, because, you know, you don't want it just sitting there; you want it doing something, you want it to enable some activity [...] it made museums, you know, and galleries ask lots of really good questions, like, you know, the kind of opened resource, whether or not we give our images for free. (Marketing manager, CS3)

Across interviews there was a sense that museums are currently not fully exploiting these possibilities and need to be more responsive, and that digital can facilitate this responsiveness. However, all museums pursued digital opportunities in their work with schools, research institutions, and further and higher educational institutions by providing, for instance, digital learning resources or supporting researchers at an international level. For instance, a digital learning manager spoke about the need to be aligned with the national curriculum and the important role museums play in digital learning:

Becoming a more digitally connected museum is part of our vision, but also, a new curriculum is coming to [museum name]. Part of this is that digital learning sits alongside numeracy and literacy as themes running through the curriculum and they launched a digital competence framework which all schools have to adapt to. We wanted to be in line with that and also recognised that digital learning is more important than ever with schools and young people using it more and more. (Digital learning manager, CS6) 
Providing learning materials and resources, and engaging with schools, can also give museums a competitive advantage and, thus, be part of their marketing strategy. (CS1, CS4, CS5)

In summary, there is significant evidence of a number of drivers across the museum sector that are increasing the demand for digital skills regardless of museum size. These drivers do not simply result in increased demands for digital and technical skills, but also instigate a shift in thinking about digital in a more strategic and coordinated way.

\section{Role changes and the demand for digital skills}

Digital has become embedded across all museums and, as an inevitable consequence, roles have changed to now require more technical and digital skills. Digital aspects have grown in all roles, but particularly in:

- Curatorial roles - curation, interpretation, preservation and interpretation;

- Collections roles - managing, exhibiting and sharing collections differently;

- Marketing and communications roles - engaging wider audiences in different ways;

- Education and learning roles - creating interactive learning resources, delivering online resources and producing copies of objects for learning activities; and

- IT and technician roles - developing new interactives, shaping technical infrastructures and increasing data storage needs.

Beyond these specific role changes, several museums encourage all staff, regardless of their roles, to use digital and engage with social media. In two case study museums (CS2, CS4) front-of-house staff were learning about digital skills and engaging with social media, but generally this role has limited engagement with a museum's digital activity.

For instance, one interviewee talked about how roles have changed as a result of digital demands:

So, we see digital cropping up in exhibitions. We see people talking about hashtags and wanting to know what it means. We see people wanting to include digital in exhibitions [...] without prompting. So, I knew the Imperial War Museum [...] they've just changed their roles of digital interpretation officers to just be interpretation, because they've dropped the digital, because actually, it's not a standalone thing. It fits in as part of an interpretive strategy and your digital is just one strand of it, for exhibitions, for example. (Senior manager, CS4)

Whilst there is demand for digital skills and even digital literacies amongst staff, applicants are not always expected to bring these skills; they are seen as something that can be developed as long as staff want to learn and engage. A learning and education manager at one museum (CS5) commented that as a result of the digital transformations 'enthusiasm for using digital technologies is explicitly mentioned in job advertisements in the learning team'.

Curatorial roles have changed most substantively as a result of digital. Curators are expected not only to provide content, but also to think through digital use and processing of objects as well as digital ways of engaging audiences with the collections. Digital has become enveloped into a broader portfolio of curatorship:

What I'm expecting all of the curators to do frankly with any acquisition is to have the ability to think about what we can do with that object in terms of engagement. Do we do a lecture about it? Some of them [objects] are important enough that we can do that. And we are expecting them [curators] to write online content as well. (Senior manager, CS1)

$\mathrm{IT}$, digital and screen-based tasks have become much more prominent aspects of curating: 
I now spend a lot more time on the computer; entering information; re-sizing images; finding images for PowerPoint talks, exhibitions, loans and publications. I also use digital methods for research papers. (Curator 4, FG)

[curators] spend [...] a lot more of their day in front of a screen, even though they're trained curators. That's curious, that is a curious thing, but the work is there, whatever it is, whether it's answering enquiries or, you know writing articles or doing stuff on the collections database or something. That is definitely, that's the biggest change I've seen. (IT manager, CS1)

Specific aspects of changes to curatorial work mentioned by curators included skills and expertise in: the use of digital catalogues and digital asset management systems; digital photography and image manipulation; social media; the curation of digital-born objects; (re-)presentation of information; and online communication. Curators also talked about a need to work in teams with documentation officers and data specialists around legal issues (such as data protection and copyright, putting collections data online and managing these data).

Many of the changes described are welcomed by curators, or even enjoyed:

I love 3D scanning. Doing them, sharing them and passing on my knowledge to volunteers. It helps us to shed new light on objects and interpret them in a new way. It means we can share our objects with anyone, anywhere and increase access. (Curator 3, FG)

Curators recognised that digital technology and developments allow greater transparency in their work and have made parts of their work easier and more efficient. For example, keeping records and documentation; doing research; and professional networking and collaborating.

I appreciate the opportunity to access online research papers; articles and collections data from other museums and specialists [...] I particularly like the improvements in digital imaging techniques and this has been really useful for my own research and for exhibitions that I have curated. (Curator 4, FG)

Across collections roles, interviewees recognised that job roles had changed to incorporate tasks that would require digital skills. However, these skills or tasks do not feature highly in job descriptions, partly because the current job holders were appointed before digital aspects of the roles became important. One senior manager explained that while digital skills were needed for collections roles, they were looking for:

more of an outlook [...] than anything specific [...] I think, in a sense, if you can get the mindset right first so that we're not thinking of digital as a separate thing and so it does come naturally. (Senior manager, CS1)

Across all museums, for those engaged in digital engagement and marketing the most commonly reported specialist digital skills demand centred on social media and engagement tools, such as: social media platforms; digital music platforms; Radio-Frequency Identification (RFID) technology; Collections Management System (CMS); email platforms; third-party applications; and augmented/virtual reality. Across marketing and communications roles, the demand for digital skills is high, and it was evident that digital literacies are increasingly recognised as important. Those in marketing and communications roles were expected to be able to design and develop strategies, policies and guidance to ensure a coordinated and considered response to digital. They were expected to have confidence in using digital as part of their role and to think 'digitally' and make the museum's work innovative, creative and engaging. Their work therefore also required a broader understanding of the impact of digital and the role of different digital communications media, for example knowing which channels and tools work with which audiences.

Staff in education and learning roles have also noted a digital-related shift in, for instance, delivering schools programmes and learning resources. For instance, one learning and education officer noted that with more pupils using technology in the classroom, the museum's schools programme had had to be adapted and is making use of: 3D scans of museum objects; 3D printing so students could handle objects; and open source software. The aim is to encourage and inspire creativity. 
Lastly, the role of IT teams across all of the case study museums has grown in breadth and depth. IT and technician roles are continually changing in response to technological advances, and there is growing demand for skills, knowledge and expertise to maintain, update and futureproof museum IT infrastructures and networks, server administration, and data storage. The technician role has changed from managing $\mathrm{AV}$ equipment to designing, managing and implementing digital interactives as well.

Notably, in the case study museums, roles had not only changed because digital technologies have driven the integration of new digital activities or tasks into staff's portfolios. A key change within roles has also been that new technologies and digital skills are improving efficiency and fostering new ways of working: '[digital] is a way of doing things as opposed to changing things based on it' (Curatorial manager, CS2). Digital technologies have facilitated a more collaborative, team-based work environment - a change that is not digital in itself but has changed roles, and consequently skills demands, as a consequence of digital technology:

Documentation people have worked a lot more closely with people like the records manager, and the registrar [...] in the past few years than they previously did, because of the scale of what we're putting online. (Content manager, CS5)

In small museums, roles had changed driven by similar influences. Small museums were expanding their digital activities beyond the basics of having a good website or a digital collection management system, and they were conscious of the demand for digital skills arising from these expansions. The importance of the museum's social media presence had, for instance, motivated one of the small museums to hire a member of staff who will spend half of their working day on social media. Generally, as noted earlier in the section 'Deployment of digital skills', staff in small museums tend to be responsible for a number of tasks, and managerial roles tend to have a stronger digital task element. Consequently, the demand for digital skills often coalesces in posts that are not necessarily digital-specific. Size and resource implications are actively considered, for instance in relation to 'future-proofing' the choices of systems and programmes:

We don't want to get into a situation again when we have a working catalogue that cannot be added to and we have to take everything out of it and put into a new system. (Small museum representative 1)

\section{Digital understanding and literacy demands}

Across all museums there was an emerging recognition that there was more to digital than skills, with some interviewees explicitly identifying digital literacies as important. Understanding of digital literacies, however, varied between and within museums. While some museums were starting to demand a greater understanding of digital skill and digital literacy, others were still focusing on demanding and developing digital skills and were less clear about how the broader digital understanding or digital literacy might be developed.

The demand for broader digital literacies in addition to specialist skills was visible, for instance, in the initiatives of two case study museums (CS2, CS4) aimed at enhancing and encouraging greater engagement with online audiences. To improve engagement these museums wanted to do more than post news, events and information on museum objects and saw digital as a promising opportunity to share and tell stories about objects and collections. However, doing so requires specialist digital skills that support co-creation, sharing and storytelling, i.e. digitally literate narrative skills:

I think it's not necessarily just about being able to log on to Facebook and/or to be able to code a website, or technology, but I think it's more about having skills to tell stories, having skills to tell stories in different ways, depending on what media is available and what media is usable. (Curatorial manager, CS2)

There's one thing missing, maybe it's actually more people who can tell stories. I'd rather, I mean one of my plans for the next four years is to come to develop that skill, but actually that is 
something that I'd really like to develop, the ability to write or produce a narrative. (Digital manager, CS2)

In this example, engagement activities resulted in a demand not only for specialist technical skills (e.g. relating to programmes or platforms), but also for specialist digital literacies that enable the interpretation and sharing of information in unique ways that improve engagement and learning.

Another example of the need for a specialist literacy that was frequently mentioned across museums is an understanding and knowledge of intellectual property (IP). Digitisation and sharing of collections, and also the general use of digital material produced by the museums themselves or by other content producers, require staff across roles to at least be sensitive to intellectual property as a potential issue. A considerable number of roles require more advanced digital literacy in the form of legal knowledge about how intellectual property rights might affect the use and reuse of content or affect the museum's work and digital agenda.

Overall, it is evident that the demand for digital skills and broader digital literacies evolves as museums' digital activity and understanding matures. Across the case study museums, digital literacy is being better understood, but this varies greatly across the museums and across the workforces. There were limited examples of where digital literacy was well developed. If this is recognised as a particular challenge for larger museums, then the challenge for smaller museums may be greater.

\section{Future skills demands}

Across museums, interviewees imagined the museum of the future to have both a physical and an online space. The physical space was not necessarily expected to change fundamentally, given that museums will likely continue to have a responsibility to collect and preserve objects. Interviewees described the future museum as a social space in which people can meet, engage with the objects and get involved with interpreting and presenting information on the museum's collections. In this context, digital can facilitate new and innovative interpretation of objects, help broaden audiences and deepen engagement and interaction. Social media and digital communication were seen as supporting this process.

However, interviewees thought that technology would most likely not define a visit to the museum. They expect technology to be used on a visitor's own terms and especially to personalise their visit (whether to the physical or online space) and create individualised content through, for example, tagging and QR codes. For instance, following an example from a US museum, visitors might use their mobile device to pin their location around the museum and thereby create a personalised collection of online digital materials that they can explore at a later date. Personalisation can provide 'a much more unique experience for visitors' (Learning and education manger, CS2). With more people using mobile devices in the museum and Wi-Fi access provided throughout, museums can push notifications and content to users as they walk around the museum. Personalisation appears to be key to current thinking about how museums may develop their digital activity in the future. If this trend developed further it would likely result in high demand for digital and technical skills in creating, publishing and sharing digital content to support personalisation technologies.

Another area of digital that interviewees expected to be a key element of the future museum was augmented reality (AR) and virtual reality (VR), for instance in the form of interactive screens with 3D scans of objects. One interviewee spoke about a museum visit not being about entering and leaving the museum, but the online and the physical being connected and part of the same experience. Another spoke of 'solid things' being embedded within or complimentary to 'digital things' (Learning and education officer, CS2). Some interviewees suggested museums' online spaces might be very different in the future, with more interactive features and moving beyond mere presentation of information. For instance, museums could assume the role of digital publishers, creating digital content designed for museum audiences. Some museums were already using live streaming and were looking to expand that activity in the future. 
More generally, interviewees thought that to meet and drive future developments in digital, museums will need to have the skills and ability to be more responsive to digital and visitor (both physical and online) needs:

Having the capacity to be agile. I know agile is obviously going to become quite an increasingly narrow term, but I mean it not necessarily in the kind of fixed methodology scrum type thing. But just the ability to work more iteratively. To actually understand what's working and what's not, what the user needs are and to actually make those decisions and change. (Digital manager, CS2)

It [the museum] could be more responsive and more reactive to its audiences and its audience's needs and wants. It could be collecting things that are relevant for local communities. So, having collecting panels. [...] Having communities involved in decisions-making of what we collect, and who for, and why. (Learning and education manager, CS2)

In terms of future skills demand in specific IT roles, there was a range of perspectives on where digital should sit within the museum and who should take responsibility for digital (see, for example, the earlier discussion on the distribution of digital in section 3) and how this may change roles. For example, an IT manager (CS5) and an IT officer (CS1) predicted that in the future there would be greater demand for more specialist roles, such as web developers and software engineers who have specialist skills and an understanding of how to develop and progress digital activity.

However, interviewees also saw the future museum as having a digitally confident workforce overall. Roles have and will continue to change, which means the demand for specific digital skills will shift. For example, a curator said that in the future it was about ensuring people were not afraid of digital and that it was seen as 'a great tool to use' (Curator A, CS4). Others spoke of the need for the museum workforce to understand the 'nuances' of digital in order to benefit (Senior manager, CS4) and to see it as their role to do 'both the physical and the digital' (Web manager, CS5). Overall, whilst the demand for digital skills is likely to continue, the need for digital literacy is increasingly understood as important. Thinking through how museums respond to changing roles and new demand, there is a growing recognition that a workforce with digital literacies would be more adaptable to digital and technological shifts.

\section{Supply of digital skills}

In the skills ecosystem approach, supply is used as a lens to understand how digital skills are brought into museums. In other words, how are staff recruited and retained who can provide the skills required? Questions of supply thus relate to an organisation's ability to attract staff with the right skills, expertise, knowledge and/or qualifications, for instance through offering salaries commensurate with the same roles in other sectors, but also relate to career pathways and strategies that focus on retention.

How the supply of digital skills is approached depends crucially on how digital is distributed and managed in the respective museum (see section 3 for more discussion). However, while - as the previous sections have shown - across all case study museums, roles have evolved to have some kind of digital element and 'digital' is expected to be part of everyone's skill set, there was also a widespread view that those skills are not in ready supply throughout the workforce.

The following sections present evidence on how digital skills are supplied in the museums, focusing on:

- Qualification profile and professional experience of museum workforce;

- Workforce turnover;

- Recruitment;

- In-house skills supply; and 
- Buying in skills.

\section{Qualification profile and professional experience of museum workforce}

The workforces of the case study museums have varied professional backgrounds, ranging from specific museum, history, design, education and art qualifications to professional experience gained throughout the culture and education sector. Staff in specialist roles, such as marketing and IT, often have role-specific qualifications. However, if staff inherited or developed into these roles, they were more likely to have a museum or cultural sector qualification and/or experience. One interviewee (CS6) spoke of the importance of having cultural awareness and language skills as well as professional qualifications, which is illustrative of the need for a range of expertise being supplied to the sector.

Few of the case study museums' staff members had attained a specific digital or digitally related qualification. Most staff had either developed digital skills within their role or were supplying skills developed previously, in another role or a job elsewhere. A digital officer (CS5), for instance, described them self as supplying traditional museology skills with a 'digital bias'.

\section{Workforce turnover}

Across the case study museums, there is generally a low turnover of staff. A few museums had seen short periods of higher turnover (for parts or all of the workforce) in response to organisational changes and/or restructuring. Only one case study museum reported a high turnover of digital staff, and this was attributed to a high number of local opportunities remunerated at a higher level than is possible in the museum sector.

Low workforce turnover indicates the need for development and skills training for staff, as well as attention to succession planning and knowledge management.

\section{Recruitment}

Complementing the low workforce turnover, recruitment levels across most museums are comparatively low. Recruitment especially into digital specialist roles is considered challenging. Across the case study museums management staff reported not being able to offer attractive salaries and, in some cases, location as an issue for attracting staff. Attracting applicants with highly sought skills, knowledge and expertise, such as web development and film production, is difficult. Recruitment processes can be drawn-out generally. Also, getting approval to recruit can be difficult and permission to replace retired staff has not always been given. Across a number of museums, it seemed to be accepted that when staff leave, their responsibilities are often incorporated into another staff member's role. This was particularly the case in smaller museums and museums with limited resources or opportunities to recruit. In these instances, some museums have recruited apprentices and/or volunteers to address skills needs:

[we] regularly have apprentices. At the moment they have an apprentice in the [name of department] a [...] junior content producer [...] Their role is to put content on the website and support website development. The apprentice liaises with other departments. Roles include [quoted from the description]: content development; storyboard; capturing and editing [something] across digital platforms [...] evaluation [analytics]; broad understanding of the media landscape. (HR manager, CS1)

In those museums where digital is distributed and seen as a shared responsibility, digital skills and competency are slowly becoming embedded in vacancy advertisements as part of the job description, and as 'essential' or 'desirable' criteria:

At one point I was like [...] we've got to start including digital literacy in every role that was [sic] advertised by the museum. But actually, l've got confidence that a lot of the managers will see that applying that competency within their own subject areas is probably more valuable than me putting a random strapline in about being digitally competent. So, they can focus it around say, 
with a curator, experience of making, producing content for social media. [...] They'll own that. (Digital manager, CS6)

In another case study museum (CS3), the training and development officer emphasised that candidates for the digital team are expected to present a reasonably detailed skill set that is not just technical, but also includes experience of digital activity, such as for example:

[...] doing social media on behalf of an organisation and, you know, following brand guidelines, and making sure things are adhering to a consistent tone. (Training and development officer, CS3)

Across the case study museums particular shortages were noted to exist in relation to photography, film-making and producer skills, which are often bought in. However, one museum (CS6) suggested that they were considering undertaking a digital skills audit in order to better understand the skills available within their museum. Whilst considering this audit strategically important, they had not had the opportunity to do it.

\section{In-house skills supply}

All of the museums tried, at least to some degree, to supply skills in-house. Using, translating and developing in-house skills can be achieved through internal recruitment, informal development and, to a limited extent, formal training (to be discussed further in section 5, Development of digital skills). Examples of flexible in-house skills supply are, for instance, a digital officer (CS6) blogging for the museum and national media while working in a non-digitally oriented role, and a digital learning manager creating digital outputs when they were a learning officer:

Before I came to this role I kind of took it upon myself to work with the digital team to recreate our learning website in a way that would allow learning staff to update information [and] to upload resources. (Digital learning manager, CS6)

There was also evidence of staff rotation, either to fill gaps or as part of organisational restructuring, which tended to result in roles expanding and some staff being overburdened.

Where museums use internal recruitment mechanisms, it is seen to be cost-effective, and an alternative to external recruitment. Importantly, internal recruitment ensures that knowledge and skills are retained:

I think the museum [...] relies on the digital skills that people bring with them, you know, and so we get good at things possibly by accident, or just because one person has those skills, and what happens when that person leaves. (HR manager, CS5)

Across the case study museums, interviewees spoke about museum skills and how in-house skills could be developed and translated into digital skills and competencies. For instance, one digital manager said:

We do lots of internal trawls, because we can skill-up on the digital side of things [...] but that background in, maybe, [name] history is quite handy for us [...] and they understand the institution. We're very fortunate to be able to shift people around. (Digital manager, CS6)

Another gave an example of how information processing skills translated into a digital skill relating to metadata:

[...] the ability to understand data is quite an important one because obviously I do all the reporting from our various digital activities, most of which seems to be web analytics and Google analytics and social media platforms as well. So, I think having the ability to not just add up the numbers in a spreadsheet, but actually tell narratives for them, which is where it's important and quite a skill [...] also taps into that sense of not just knowing where to get the data, but how to put it into context and how to actually convey its meaning. (Digital manager, CS2)

Other managers spoke about 'interpretation' as a museum skill that could facilitate online co-curation through outreach and community projects. Co-curation is common practice for most museums, but it 
is not something that is communicated well or widely recognised. One manager spoke of the need for better interpretation in order for the museums to be 'brought to life' (Learning and education manager, CS2).

However, using in-house resources can have hidden implications for the overall supply with digital skills, as the example of one case study museum (CS2) illustrates. In this museum, an in-house team looks after the museum's website infrastructure, platform and content, and programming. The demand for web development skills is less straightforward to cover, though. There are no resources to buy-in web development skills, so the team have worked creatively to meet the demand by using and building on in-house skills:

I can see an argument that like some museums, for example, you might have a team of actual web developers working here or people who could do things like more direct coding and actually building things. But I struggle to see how that would work in the scale of the organisation we are. It seems to make much more sense to contract that in where we need it, or what we often do is actually work within the ordinances of what we have, so when we are doing something digitally it often ends up being a WordPress site. (Digital manager, CS2)

At first sight, this account looks like a good example of a digitally confident person building on their digital skills and applying them to a 'new' technology. However, as the digital manager commented, this reliance on in-house skills also carries the risk of limiting digital activities and the development of digital skills:

And that's just because I know [a WordPress site] is cheap and easy and we can actually do it inhouse and therefore concentrate on the content rather than the technology [...] So, there is a danger there perhaps that we in fact may limit what we do in terms of in-house competencies and be slightly blind to what capacities we need to expand. (Digital manager, CS2)

For smaller museums with limited resources to recruit or commission, drawing upon in-house skills and expertise is vital for their ability to engage with digital activity and projects. In these museums, interviewees spoke of all the workforce (paid and unpaid) contributing to digital activities, especially in public-facing roles. One interviewee said that it is often a small number of staff whose work is critical to the success of a digital project and the digital activity of the museum, including directors to provide the strategic overview, plus those in marketing and communications, collections and IT roles.

\section{Buying in skills}

Another approach to skills supply used by all museums was commissioning and drawing upon networks of agencies and freelancers. Buying in skill supplies was especially common for bigger projects and/or in the museums that were well funded. Key areas of bought-in digital skills were photography, film-making, web development and content editing. A small museum spoke of the need to buy in skills to ensure that their new website was accessible to their key audience, who are likely to have a disability.

Four museums (CS1, CS2, CS3, CS5) had hired specialists on short-term contracts or contracted agencies to supply specific skills that could not be supplied in-house, often tied to specific projects:

When we've got big capital projects like opening a new gallery, where there's a lot more demand on our team to kind of do content that goes into the gallery, we'll sometimes get short-term members of staff for, like, nine-month contracts. So [...] this time last year [...] we were a team of eight, so we had a film-maker embedded and someone to help us with the content and another producer. (Digital manager, CS3)

Buying in digital skills was also a common supply approach for small museums, where human resource provision overall is more constrained and in-house supply may cover some technical areas but not others. A member of staff who provides technical support, for instance, may not have the skills to contribute to other facets of the museum's digital activities: 
we have to use contractors and I'm thinking about moving to entirely contractor-based provision [of IT services], so that we get cutting-edge service. A member of staff cannot be constantly on the cutting edge of digital developments. (Small museum representative 1)

However, it was recognised that once the contract is finished, the skills are often lost and would need to be bought in again.

\section{Development of digital skills}

Lastly, the skills ecosystem approach draws attention to development and asks how skills, competencies and expertise are nurtured, supported and encouraged. To understand a skills ecosystem, it is important to explore the current practice of developing skills development and addressing gaps. Whilst digital literacy is, to some degree, becoming integrated into roles within the museums studied, there was little to no evidence of formal or planned training around digital skills or digital literacy. Formal and informal training were used to upskill and reskill staff and volunteers generally, and much of the digital skills development activity was informal; for instance, staff supporting each other and sharing skills, or staff learning on the job. Few of the case study museums had formal, or what can be considered traditional, approaches to developing digital skills and competencies. Formal training is sometimes provided when a clear skills need is identified or new systems are implemented. Staff are also financially supported to undertake training outside the museum, such as attending professional conferences. Overall, digital skills development tends to be on an ad hoc basis. Most training is designed to meet specific needs and often carried out on a oneto-one basis when requested.

Across the museums the need to upskill and reskill in terms of digital was recognised. It was also acknowledged that staff who are digitally skilled need to better understand and exercise their digital literacy. The following sections explore the development of digital skills across the museums studied, focusing on:

- Identifying digital skills needs;

- Skills development programmes and practices;

- Informal and peer learning; and

- Partnerships, professional networks and conferences.

\section{Identifying digital skills needs}

Across all of the museums, there was no evidence that museums are undertaking an organisational assessment of digital skills needs. As part of their involvement in the 'One by One' project, some interviewees reflected on organisational knowledge of digital skills and the needs for future skills needs assessments:

Reading your information [about the One by One project], I realised how little I know about the digital skills that we as an organisation have, that we as an organisation need. And that's a hole for me, because [...] we should be a part of identifying skills gaps of all kinds, and if there is a digital skills gap, we should be helping to fill that and develop people. (HR manager, CS5)

Three case study museums (CS1, CS5, CS6) were aware of the strategic importance of a digital skills needs assessment or analysis to identify in-house digital skills, but they had not yet progressed these plans. Overall, assessments tended to be rather informal and basic, supplemented with recognition of the need for a more formal articulation; for instance:

To be honest I think we're not badly off [...] I think the level of knowledge is pretty good and we do have people who want to do stuff [digital activity] and I think it's just getting an overview really and getting it up and running. (IT manager, CS1) 
Others noted basic digital skills shortages within the museum that needed to be addressed:

The biggest problem is not digital media skills, it's just bog-standard digital skills [...there is the] assumption that everybody knows how to use computers. People don't know how to use a computer. [...] We, as an organisation, have forgotten people need to be shown how to use it sensibly. (IT manager, CS3)

Importantly for skills development, the museums have adopted digital technology gradually and over a longer period of time, which has meant that technical and digital skills have been learnt and developed slowly, lost when staff left and brought in with new recruits. Determining 'exactly' which digital skills or development initiatives are needed can, therefore, be challenging. These dynamics suggest it would be beneficial to shift thinking to digital literacies and to making staff confident in approaching digital activities regardless of how digital tools develop.

In most of the case study museums, skills needs are regularly identified and addressed through oneto-one development reviews. It is through these conversations that staff identify their skills and learning and development needs, as well as getting support to meet these skills and development needs. Training needs are often also identified at project team meetings when progress is reviewed. Some interviewees described how curators in their museum had lobbied for a particular type of skills development:

This year they are rolling our photography training to curators. [...] Curators have been asking for this training for years; it was spurred on when our collections went digital. (Curator 1, FG)

Notably, training and development was mostly ad hoc and in response to a specific skills need.

\section{Skills development programmes and practices}

The case study museums run a variety of formal and informal skills development initiatives to skill, upskill and reskill staff and volunteers. Some case study museums had IT learning and training rooms, plus learning and development programmes that provide basic IT skills training. The case study museums were found to variously offer training and support on: how to use IT systems; digital content creation; writing for the web; using social media tools; using online editing tools; evaluating, understanding and using web analytics; using content management systems; and editing and manipulating digital images. There was growing recognition of the need for a formal digital training programme: 'specific training [is] something that I think we need to put more thought into' (Senior manager, CS1). Some interviewees stated they would benefit from more in-house skills training, but that it was limited by stretched resources.

Skills development programmes such as induction training and training on new systems targeted all members of staff. For instance, one museum (CS5) provides induction training that introduces the museum's IT system and covers the Freedom of Information (FOI) Act. When IT systems or tools affecting most members of staff are changed, training tends to be 'rolled out' in the whole organisation. In one case study museum (CS6), training was provided to all staff when a new HR system was introduced. This training was provided by HR staff using a tutorial method, which was delivered on a one-to-one basis with the support of online manuals and highlighted the lack of IT skills of some staff:

A lot of those staff who are not regular PC users, actually are not very confident users either. So, we're going to pair [the introduction of the HR system] with a lot of basic level training in terms of using computers. And we're working with a local college to [...] do that basic training. How to turn a PC on, where to go, how to use the internet. [...] If there are sufficient numbers internally, we will bring [the training] in-house. (HR manager, CS6)

A variety of practices support digital skills development in the case study museums, including regular, bite-sized training opportunities such as drop-in sessions or workshops. These are often considered to be more useful and accessible than longer courses that are run a few times a year, as noted by an IT manager: 
When you are looking at technologies like Office 365 , it changes so rapidly that trying to do a defined course and the course material [becomes out of date]. Whereas, if you can do workshops and get people on there and get them to immerse themselves a little bit and start working, that can be a good way to learn. (IT manager, CS5)

A learning and education manager saw confidence as the key development focus rather than a focus specific digital skills or literacy:

I would even say digital confidence is what we need to build. Because if somebody suggests for you to go and write a programme about it or you could come up with a programme to automate something - the sense of 'I couldn't do that' once you get people to work it disappears. It's the confidence rather than the literacy. [...] For me digital confidence is about rationally exploring various options on the table as opposed to generating all of those things yourself. (Learning and education manager, CS1)

Most training (formal and informal) to develop digital skills and competencies in the case study museums is organised at the departmental or individual level. Digital skills, and where they might be deployed across the case study museums, are often not part of the induction for new staff. However, digital teams (CS1, CS2, CS3, CS4, CS6) try to work with people as they start their roles, at which point embedding digital has proved to be easier. The HR professionals who participated in the research described various types of training and development programmes that have a digital element, but most said there is not an 'active digital strand' (Content manager, CS5) within their learning and development portfolio. In one case study museum (CS5) digitally oriented training is delivered by the web team, which also provides a range of manuals to support continued skills development. This training is designed for staff who produce online content:

We in the team train all editors and web authors, where a person actually has an actual job and then they're asked to contribute on the website by producing content from their department [...] So, this is the digital training that we're providing people. (Web manager, CS5)

Some interviewees noted that they needed to spend time outside working hours to keep their digital skills up to date; for instance:

Yes, you're always just picking on these things as you sort of go along. And then the stuff is there for us to use, and because [...] most of it's open source, I can then go home and keep my learning up at home. So, I do tend to, I mean, personally, I try and stay as much up to date with digital as I can [...] I think it's important professionally, but I'm also personally interested. (Curator B, CS4)

Curators reported undertaking various forms of training to upgrade the skills needed for digital activities. Some of this training was reported to be provided by external agencies, while others described training provided by their colleagues:

At our institution we can attend training sessions for social media and blogging. We also get training on [name of software] by our collections services team. I would say this is all useful. (Curator 1, FG)

\section{Informal and peer learning}

Across all of the museums, digital skills and literacies are mainly developed through peer learning, the informal sharing of knowledge within and across museums, as well as in museum networks. There was a noticeable collegiate attitude towards supporting the development of digital skills and confidence in using digital tools. Interviewees spoke about colleagues having different technical and digital skills, and commented that there was always someone around to help and provide advice on technology implementation. This openness to peer learning is emphasised in one museum's social media strategy, which explicitly states that one-to-one support is on offer. Across museums there was a strong sense that a big part of encouraging staff to engage with digital has been about demonstrating the possibilities and instilling the confidence to use tools. For example, a senior manager spoke about how staff were good at engaging with Twitter after individualised support: 
I remember saying to [colleague's name], why don't you tweet? [...] and she went oh no, I don't do that sort of social media stuff. Now I can't keep her off it. And she's brilliant at it, and the way she engages is great [...] And we introduced her to some of the hashtags about, you know, Fossil Friday and Throwback Thursday and [...] she suddenly went, actually, I can see the point of this. I can actually communicate to people, and they can see what I'm doing. (Senior manager, CS4)

An important element of this informal approach to the development of digital skills, particularly social media skills, was sharing information and showing staff how people had engaged with the museum. Staff who had been able to see engagement with their own content (i.e. projects, collections, exhibitions, objects) were more confident that their digital work was of interest to the museum audiences and they felt encouraged to produce more digital content.

Several case study museums use such 'enabling' approaches to improve the digital literacies of staff. For example, in three of the case study museums (CS2, CS4, CS6) web and social media statistics are available for all staff to ascertain the popularity of the content they have produced. Rather than digital team staff producing and sharing the data with them, staff may be given direct access to dashboards and are encouraged to experiment and explore the data. The case study museum (CS6) that uses this approach has found it successful in encouraging staff to engage with digital. Another museum (CS4) regularly shares examples of successful, engaging content with all staff creating online content, both to recognise good work and to further encourage and 'embolden' staff. Such museumwide conversations about content or innovative digital activities also contribute to 'mainstreaming' (Digital officer, CS6) digital. Advanced social media users become part of the museum's informal network, and are encouraged to support other users and act as advocates of digital:

It's thanking and acknowledging those high performers so that their visibility as digitally competent people within their departments is elevated [...] So that [...] they become more empowered in their own role and when other people come to them to say, well, 'could we do this on social media' or 'could we do this on the website?', they're in a position where they can say yes, no, maybe. (Digital officer, CS6)

In another case study museum (CS2) front-of-house staff are often involved in the design, development and implementation of new systems to be used by them, such as audio guides and mobile applications. Such mainstreaming of digital was considered a successful way of developing staff's digital skills and confidence with digital activities.

In some of the case study museums (CS4, CS5), the sharing of digital knowledge and skills took place both informally and formally as part of regular meetings. This was considered beneficial and a good way to learn what others were doing in terms of digital activities. In one museum this meeting-based sharing no longer took place because of time constraints, but they were considering arranging 'lunchtime learning sessions' if there were enough appetite for this type of informal learning and sharing (Digital officer, CS5).

\section{Partnerships, professional networks and conferences}

Across all of the case study museums, staff were supported financially to attend external training courses, workshops and processional conferences and to visit other museums to share practice and learn. Digital skills development through professional networks and at conferences is considered successful, and conferences are integrated into project work in order to facilitate knowledge influx from the sector. Interviewees also said they took part in partnership projects in order to learn and develop new skills.

Partnership and professional networks are particularly important to small museums and the development of their digital activity and skills. Representatives of small museums felt that their museums have benefitted from the regional museum development networks and that the 'digital officers' of these networks were a good conduit for informal networking. It was evident that a good digital officer understands the constraints, challenges and opportunities of small museums. The 
interviewees at small museums also highlighted that their digital skills development has benefitted from the general openness within the sector:

There is old-fashioned friendly openness in the sector. You might help someone, and they'll help you. We're are not competing for business. (Small museum representative 2) 


\section{Conclusions}

\section{The digital skills ecosystem in UK museums}

In the previous section, the skills ecosystem framework was applied to evidence on the deployment, demand, supply and development of digital skills in UK museums. As described in section 5, the picture for each of these four dimensions is far from static: digital technologies and opportunities develop, as do museums' engagement with them, and both impact the deployment, demand, supply and development of digital skills in the museums sector workforce. Consequently, at sector-level too the ecosystem for digital skills in the UK museum sector is a dynamically developing one. This section brings together empirical evidence from the case studies, focus groups and interviews in an overview of the digital skills ecosystem for the museums sector and highlights the key dynamics in the dimensions deployment, demand, supply and development (summarised in Figure 1 below).

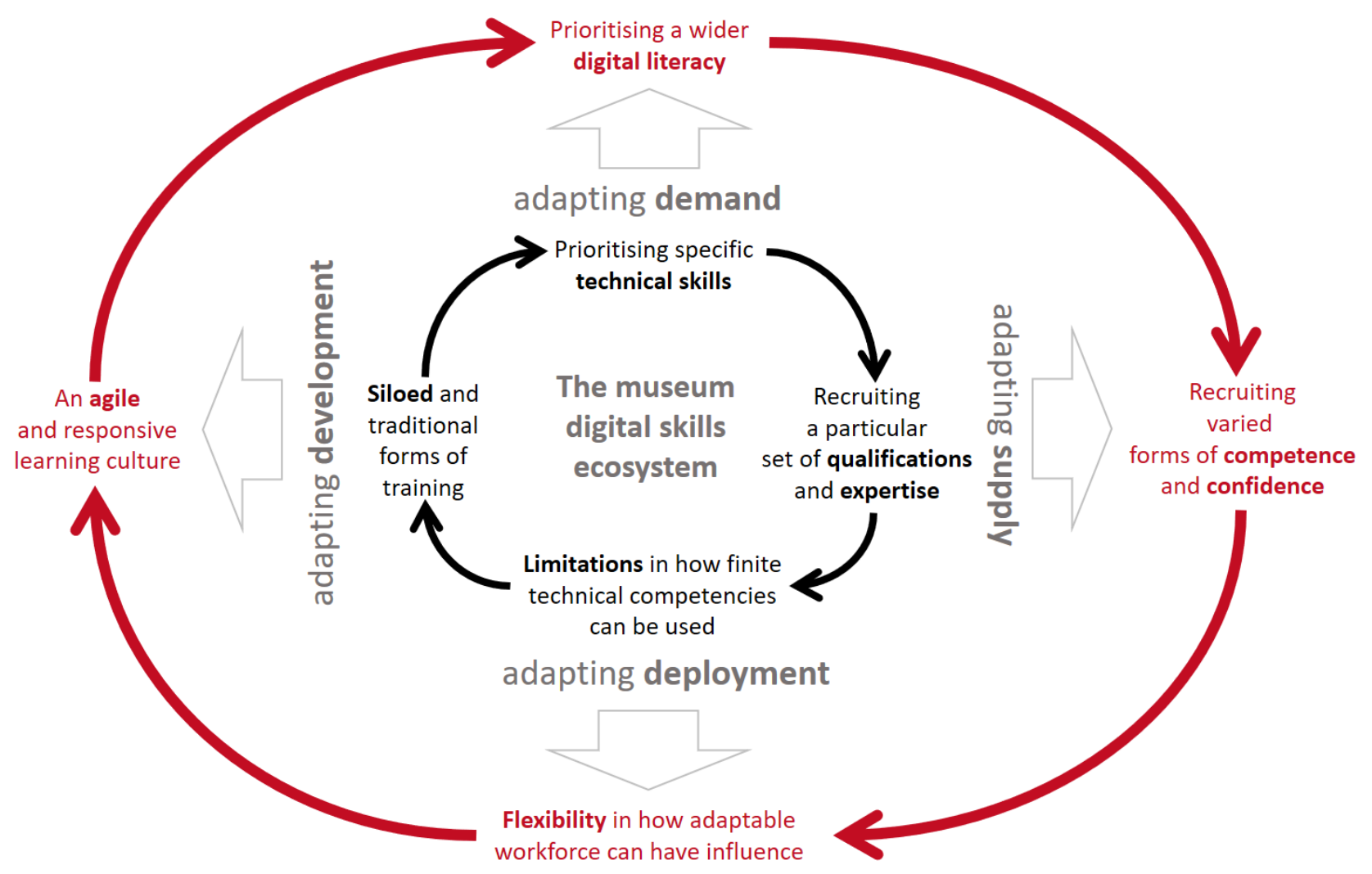

Figure 1 The museum digital skills ecosystem 


\section{Deployment: from 'limited use' to 'flexible influence'}

In skills ecosystems focused on technical skills, there can be limitations in how broadly or variedly these skills and competencies can be used or deployed. Our evidence showed that in the UK museum sector, tensions between specialist technical skills and generalist digital skills and literacies are the key aspect of digital skills deployment. Digital skills are typically deployed in four main museum activities. First, digitising collections and opening the digitised records up to a wider public audience. This area of deployment requires knowledge of digital archiving and databases, as well as expertise around intellectual property and copyright. It draws mainly on the skills of a reasonably small group of specialists. Second, digital skills are used in web presence and social media activities. The skills deployed here range from those provided by specialists (for example, web usage statistics, audience engagement techniques, and the production of specialist content), to more basic skills provided by a wider range of museum staff and volunteers (such as contributing tweets and Instagram posts).

Third, the use of digital technology in exhibitions, as well as learning and outreach activities, requires the deployment of digital skills at the interface of specialist AV and IT skills (how something can be made to happen) and curatorial/pedagogical skills (what works with different audiences). Fourth, digital skills are used in operational management and communications activities, from electronic communication and sharing of files and calendars to learning resources and HR selfservices. The skills deployed on this fourth set of digital activities are, to a large extent, not specific to museums.

The deployment of digital skills across this range of activities means that a number of traditional museum roles across have changed (see also MU.Sa, 2017). There is a shift from singular and localised responsibility to collective and distributed ownership of digital across the organisation. Digital is increasingly part of everyone's roles and some case study museums have recognised the need to mainstream digital into all their activities and connect digital into all considerations. Digital is increasingly not additive but constitutive, and part of the initial thinking and conversation around new exhibits and displays. A digitally confident workforce will arguably be adaptable and able to shape how technology is adopted and used across a range of museum activities. The key dynamic in this dimension is, therefore, from a specialist deployment of digital skills to a distributed deployment of specialist and generalist digital skills and digital literacies across all roles in a museum.

\section{Demand: from 'technical skills' to 'digital literacy'}

Traditionally, demand has been for a workforce with technical digital skills (such as AV maintenance, web programming languages, database management) specific to the needs of the organisation and its activities. This demand for technical skills may have been prioritised where financial constraints limited the ability to attend to expanding demand for more general digital skill sets across the workforce. 
However, in line with developments around skills deployment, demand is now shifting in two ways. First, general and specialist skills are required across a broader set of roles and activities. Second, while technical skills are still relevant, digital literacies are also becoming crucial. Audiences' increasing expectations in relation to digital and the need to reach wider (and new) audiences have resulted in, for example, demands to use technology more creatively and innovatively, to be up to date and to keep up with others (not just those in the sector), and to engage with new forms of dissemination and communication. Activities such as social media, creating new forms of interactives in exhibitions or communicating live with geographically dispersed audiences raise new digital skills demands across the museum workforce. However, whilst there is evidence of museums actively addressing such new digital demands, many also expressed caution about investing (both financially and in terms of upskilling the workforce) in the latest technology. The general approach was to be curious and open,but observing and evaluating; keen to see what other organisations were doing, and to share learning and good practice.

\section{Supply: from 'qualifications and expertise' to 'competence and confidence'}

The case study museums had, in the past, recruited a workforce with a particular set of qualifications and expertise, focusing on specific technical skills. For example, curatorial staff were recruited with museology, history and arts qualifications, external relations staff with marketing qualifications and IT staff with computing qualifications and expertise. In many cases additional specialist digital skills had been supplied through specialists on short-term contracts or agencies. Notably, this bought-in supply of skills is typically lost once the contract is finished, and would need to be bought in again. Overall, skills supplies are still quite targeted and focused, which does not necessarily enable the distributed deployment of digital skills across an organisation. Some museums were therefore rethinking how skills, particularly digital, were being supplied (see also Hutchinson \& Cartmell, 2016; Shipp, 2016). For example, they were engaging young people to do social media around specific events and volunteers to fill workforce skill gaps. Museums are also increasingly recruiting individuals with a range of digital competencies and confidence, who can take on a digital task or role and competently apply their knowledge to a range of digital tasks and technologies. Prioritising wider digital literacy and recruiting 'digital generalist' brought benefits to the museums, as these generalists tended to have both a broader range of experience than specialists (for example in website management and publications) and a background of working in cultural organisations. Museums are also increasing the variety of digital competencies and confidences they recruit, and, depending on the role, creating a skills supply focused more on candidates' experience and confidence in using various digital tools and platforms, and not on their qualifications or experience that are directly relevant to the museum.

It is interesting to note that some of the museum workforce may have digital competencies when they join the museum or develop these while they are in post. Many staff had successfully deployed digital competencies, which then became part of the skills demand for their particular role. The overall development in relation to supply is thus a diversification and distribution of digital competence and confidence across museum roles. Specialist digital skills supply sits within this broader supply base; it is neither subsumed nor obliterated by it. Rather, it is supplemented by a growing supply of digital skills and literacies around it.

\section{Development: from 'siloed training' to 'agile learning'}

Developing digital skills and literacy is considered particularly challenging within the museum context. A number of factors impacting on the sector result in a high demand for workforce development, for instance technological change in combination with the need to meet growing audience expectations and remain competitive within the museum sector. As roles develop to include digital activities, requirements to upskill and reskill in terms of digital arise.

Currently, the development of digital skills within the museum sector seems to be undertaken on an ad hoc basis. Few of the museums had formal or what can be considered traditional approaches to 
developing digital skills and competencies. Most training was designed to meet specific needs and often carried out on a one-to-one basis when requested; an approach to workforce development which makes it likely that digital literacy becomes siloed and experiences not shared. In response, museums are changing these forms of development to more innovative approaches and informal learning amongst colleagues and museums. Supporting and enabling the workforce to 'test and learn' digital activities (such as social media, blogging, vlogging and live streaming) was common practice across a number of the case study museums. Museum representatives reported examples of bringing in new staff with digital competencies and confidence to support the museum workforce in developing and deploying digital skills.

Overall, a more adaptive learning culture seems to be emerging in relation to digital skills development. However, more developed and long-term programmes of support for digital literacy and competence might yet be needed. More evidence is also needed on whether embedding the development of digital literacy and competencies across museum roles results in a museum that is more agile and responsive to changing technology.

\section{Adapting the digital skills ecosystem for museums}

The early findings of the 'One by One' research project suggest much of the UK museum sector is still dominated by a technology-driven understanding of digital: digital is equated with (developing) hardware and software technologies to which museums need to react. Consequently, digital skills are understood as relating predominantly to technical skills which results in the recruitment of specialised and narrow sets of digital qualifications and expertise. Such an understanding of digital skills demands can equip museums with skills that enable some level of digital activity. But it leads to a skills supply of finite technical competencies that are limited in how flexibly they can be deployed across tasks and roles, which then leads to siloed skills deployment and comparatively narrowly conceived, traditional forms of training and development. This cycle tends to reinforce a demand for yet more technical digital skills, resulting a context in which museums create specific projects deploying digital competencies supplied by a small group of IT professionals. The corresponding relationship with digital is reactive, narrow and disconnected both from the expectations of audiences and the wider needs of museums, and typically characterised by a fundamental lack of digital confidence across the museum.

However, importantly, there is also clear evidence that this traditional digital skills ecosystem has the potential to adapt, and is already being challenged and changed to incorporate new sets of interdependencies. As outlined above, the sector is pushing towards an alternative system (if currently more in aspiration than in practice) in which museums prioritise wider digital literacies (instead of narrower sets of technical skills) and recruit more varied forms of digital competency and - perhaps more significantly - confidence. A digitally more adaptable workforce can then provide greater flexibility in how digital literacies and confidences are deployed and can shape the organisation, including to develop more responsive cultures of learning and development that in turn can sustain the valuation of digital literacy over specific technical skills. Such more progressive, more digitally mature skills ecosystems are less about generic technical skills that are determined by a higher national skill set or curriculum. Instead - crucially - they foster digital literacies that grow from below, out of the needs of individuals, within particular professional settings, in the local contexts of their specific institutions. Instead of focusing on developing technical skills within a small specialist group such as an IT team, these more mature skills ecosystems cultivate digital literacies within roles across the whole museum.

Moving from the traditional to the more mature digital skills ecosystem will require conscious changes of digital skills strategy and practices in the museums. Our research has identified a number of challenges museums are likely to face in making these changes, along with some first approaches to overcoming them. 


\section{Challenges to the deployment of digital skills}

Reviewing the roles in which digital skills are deployed in museums showed that museums do not understand 'digital' as an add-on that they buy in as and when needed. Digital is clearly written into the case study museums' role structures. Digital may not be the core skill that museums are run on, but the analysis of how digital skills are deployed evidences digital as an established part of what museums do, and will do in the future, museologically and as businesses or organisations.

That said, our analysis of digital skill deployment also uncovered typical challenges related to digital skills deployment. First, and probably most commonly across case study museums, the division of labour between staff members working in digitally oriented and 'regular' roles is contested terrain. Staff who work in digitally oriented roles felt that they were expected to cover all activities that their colleagues saw as 'digital':

People get comfortable with certain things or they get used to a certain situation. [...] Any sort of technical environment is given to the digital [person]. [...] There's lack of knowledge, or there's fear, or confusion about roles, or whatever. [...] So, we're trying to tackle that a little bit by hopefully having some training with the team. (Digital learning manager, CS5)

[the biggest challenge is] people not feeling either it's their job or that they're empowered enough to do it. [...] A lot of the time they don't need to know anything technical, [...] it's more about having that awareness and [...] having thought about the digital and having it as a part of that project right from the beginning, and then providing the information to us so that we can tweak it and make it useful on any platform. (IT manager, CS5)

A typical side effect of staff in non-digital roles not taking ownership of digital aspects is that digital specialists are brought into projects or processes at a late stage. Several case study museums reported change in this specific case of digital skills deployment, though, with projects increasingly featuring close involvement of digital specialists from the start, thus allowing specialists to better support the project:

When I first started in [the] digital [team], it was basically the last stop. So, everything got dumped, and [they] said 'Can you put this online'. [...] And then there was a bit of a kickback to say we need to know, we need to plan, we need to know that we've actually got a bit of input to say about this [...] So then [...] digital was brought in right at the start. [...] Whereas now what's happening is that I will say, I want you to tell me what the exhibition's about and what you can't do. [...] What problems can [digital] help solve? (Digital programme manager, CS6)

Such closer collaboration between digital teams and other staff has, in some museums at least, led to more distributed ownership of digital, and to a more effective deployment of digital skills. There was also emerging evidence that distributed deployment changed the perception of demand to one that recognised the need for digital literacies, which can then initiate more mature approaches towards supply and development.

A second challenge relates to time and resource. Opportunities to deploy digital skills (let alone develop them) were limited by finite time and resource, on part of the digital specialists but also their non-specialist collaborators within the museum:

There are things we could do that we don't do, not because of a lack of technical skills or even technical resources, just people simply not having time. So, for example, when we produce an exhibition and we often have lots of other content [...] and often that stuff doesn't go online because the people working on that project [...] are moving off very rapidly onto something else and the digital team [...] are wrapped up in their own roles anyway [...] and the barrier really is staff time, actually. (Digital manager, CS2)

Relatedly, constraints on recruiting or buying in advanced digital skills and literacies also limit museums' engagement with digital. Importantly and as noted in section 5, it is not the immediate shortage of skills for undertaking a certain task that is relevant here. The broader and potentially more problematic issue is that a lack of digital skills and literacies constrains the awareness of what 
tasks and projects could usefully be undertaken and developed, and what (potential or future) demands for digital skills should thus be recognised and addressed.

Overall, lack of time and resource was noted across the case study museums as a barrier to better or more extensive engagement with their museum's digital work and agenda. There was a strong sense that the possibilities for deploying digital skills are much broader and deeper than museums currently have resource or incentive to cover.

\section{Challenges to developing digital skills and literacies}

While all case study museums provide some ad hoc digitally oriented skills training (such as presentation skills, talking in front of a camera, blogging and tweeting) there is little evidence of coherent, sustainable programmes to upskill staff in relation to digital. Overall, digital skills development suffers from a lack of clear visibility and articulation of gaps and goals:

In traditional training terms, you look for what is the output that's required. You know, what skills do people require in order to do these things? And at the moment that exists in parts of the organisation, you know, they're looking at training staff in blogging skills, in on-camera skills [...] for example, but in other areas of the business, it's less defined. (Training and Development manager, CS3)

But even when it is known where upskilling needs lie and how they might be addressed, lack of time and staff resources constrain development:

So, we're going the, kind of, right way, but we do need people who know how to use the stuff. And with the best will in the world, yes, we could learn it, we could all go off and learn it, but actually we haven't got time to do that and we perhaps shouldn't be doing it with the roles that we've already got. (IT manager, CS1)

Similar issues apply to application: one case study museum (CS2) estimated that only 10 per cent of staff who had undertaken blogging training had then engaged with the medium and produced content. Staff did not have enough time to deploy their newly developed skills.

Building lasting digital literacies can also be a slower process than expected because of the frequency with which tasks requiring digital skills occur in a particular role:

So, they'll [facilitators] run that session [with schools] a few times, and then [...] for the next few months they'll do something else which doesn't use that technology. And then they come back to it in six months' time to run it again, and they've lost the confidence, or [...] they've forgotten how to do it. (Learning and Education manager, CS5)

To overcome such challenges, it is essential to have dedicated digitally oriented roles in the learning team that can then provide valuable support to other team members:

We're realising that we probably do need to have particular people looking after these activities. [...] If we reduce our dedicated digital learning staffing too much, we won't be able to give the rest of the team enough support [and] there will be a natural process of choosing not to use digital, because it's too complicated [...] people are afraid of it, or they are [...] see it as too risky. (Learning and Education manager, CS5)

There was also evidence of digital skills development, in the broader scheme of things, not having priority over subject knowledge:

Training (curators) on things like research skills or presentation skills or improving their own historical knowledge does take precedence actually and I probably would stick with that. (Collections manager, CS3)

Notably, this view is rooted in a conceptualisation of digital skills as separate from other professional skills such as research, which then leads to a hierarchy of skills needs that impedes the development of digital skills. These views were not unanimous, though. In some cases cross-cutting issues and digital skill development were seen as interconnected: 
We try and train everyone here in a basic set of data protection. [...] It actually has implications for lots of things, not just digital. But it has big implications for digital. (Content manager, CS5)

Overall there was a noticeable lack of clear, strategic approaches that made the development of digital skills and literacies a priority and provided resources (time and budgets) not just for the development, but also for the supported application of newly acquired skills. What is required is sustainable digital capacity-building in the museums sector workforce. Importantly, such digital transformation needs to be resourced as a longer-term investment; across museums interviewees described it as challenging to deliver longer-term skills development plans when budgets are (due to government funding) committed only annually.

\section{Creating a shared vision of digital}

The challenges to transforming the digital skills ecosystem discussed above apply differently to individual museums - some may find transforming skills deployment more difficult, others may encounter greater barriers to training and development. But the research also exposed a challenge pertaining to all museums: they lack a shared recognition of how significant digital transformations are for their work. Addressing the strategic and operational challenges outlined above requires staff across each museum to not just recognise the opportunities digital offers, but to also appreciate and pursue the skills, resources and mindsets required to capitalise on those opportunities. Our research showed that such shared visions were not established, and that, in particular, they were often lacking at senior management or trustee level. The non-recognition of the importance of digital skills and literacy at senior management level is especially problematic: it leads to a lack of support for digital generally and impedes resource commitment and necessary financial investments. But as an IT officer emphasised, building a shared vision is not solely the responsibility of one side or the other:

I think at the very highest level there's a lack of understanding, and therefore just a kind of, 'I don't want to make a decision about this in case it's the wrong' thing. And I think, [...] it's a twoway street, because [...] it's our responsibility to get the buy-in from the people up there. It is their responsibility to make the effort, and take the time, and try to understand, but it's as much our responsibility to make that happen, and that gap has never really been bridged. (IT officer, CS1)

In small museums, the Board of Trustees are more likely than the management to be the ones who do not yet fully understand how digital transformations have impacted on the museum. Some interviewees noted that the need to use digital to capitalise on business opportunities will remain, and highlighting the business case for digital may influence decision-makers in museums:

Unless the funding gods come back, there's no escaping the fact that for museums to survive, and to thrive, they have to become businesses, and they have to be able to pay their own way to some extent. (IT manager, CS1)

This lack of shared vision for digital is closely linked to an operational issue: the lack of digital skills audits. As outlined in section 5, museums do not have a clear picture of the digital skills they would have available for pursuing a shared digital vision - or for building one in the first place. Undertaking such an audit would provide better understanding of which digital skills and literacies are relevant and how they relate to other professional and museological skills, and, in combination with an up-to-date digital strategy allow museums to capitalise on the opportunities digital holds for achieving their overall goals.

\section{Looking ahead}

With a digital history that goes back to the late 1960s, the museum sector is about to step into its second half-century of working with computers. Over that time the advent of digital technology has changed the way museums manage collections, do research, shape exhibitions, and build relationships with their audiences. But despite fifty years of computer-enabled advancement and transformation in the ways museums work, the sector as a whole still lacks digital confidence. It still does not have the digital skills and literacies needed to meet its (and its visitors') expectations. As 
outlined above, the museums sector has to make changes and address challenges to fully integrate digital into its practice and culture.

The foundations for digital transformation are likely to be better than a detailed reading of the challenges and shortcomings might suggest. Museums have changed and continue to change in the way they do their work. As one interviewee explained for their organisation:

The museum is an innovative place. The galleries which have been developed have been developed with technology in a way which is unobtrusive and deep as opposed to technology for its own sake. I think that stems from a genuine commitment to communication and engagement and dissemination of knowledge. That is the kind of environment needed and supports intellectual growth from both staff and visitors. (Learning and education officer, CS1)

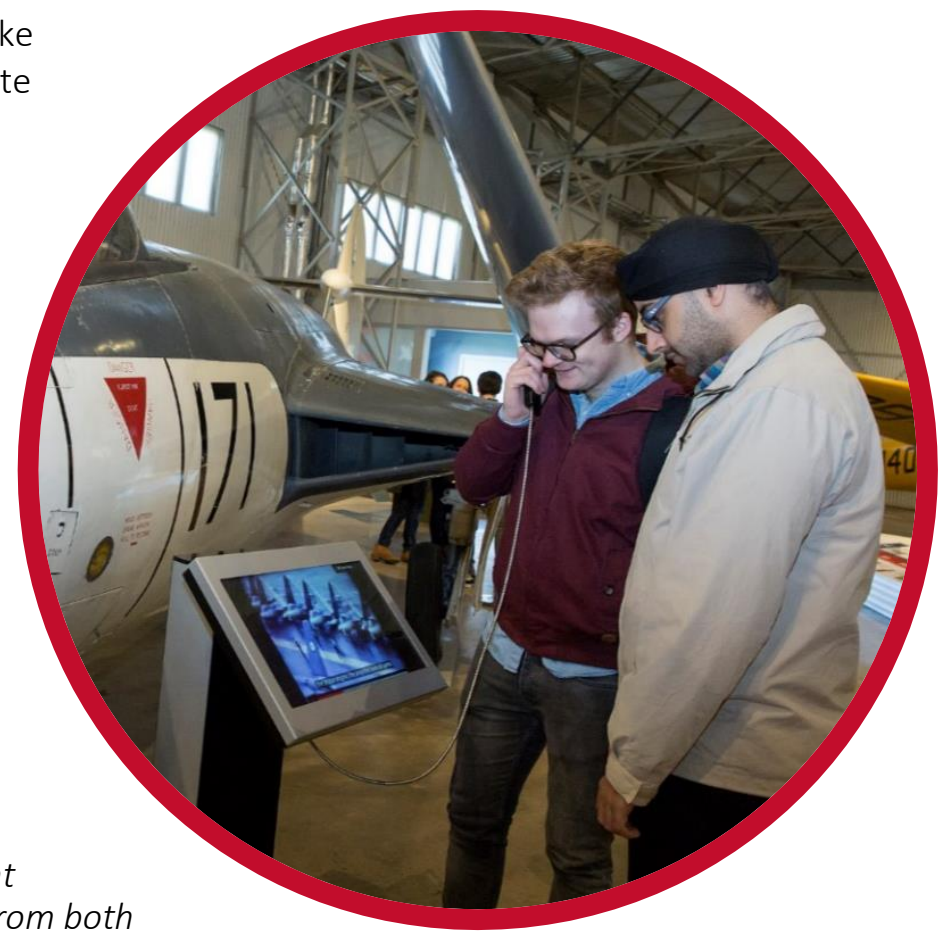

While there are clearly constraints - to understanding or resources, most prominently - that currently impede the development of digital literacies, digital is established as part of the museums' portfolios. The overall challenge is not to introduce digital but to expand the current understanding and mainstream digital into activities, skill sets and cultures. This initial research, as part of the ongoing work of the 'One by One' project, does not only help to explain the lack of digital capacity within the sector, but - tantalisingly - it is also offers an emerging picture of how the demand, supply and development of digital skills can adapt to create a transformative, innovative, creative and digitally literate workforce 


\section{References}

Amgueddfa Cymru - National Museum of Wales (2014). Digital Content Strategy 2014-17. Cardiff: Amgueddfa Cymru - National Museum of Wales.

Anderson, P., \& C. Warhurst (2012). 'Lost in Translation? Skills policy and the shift to skill ecosystems'. In T. Dolphin \& D. Nash (eds.), Complex New World: Translating new economic thinking into public policy. London: IPPR, 109-120.

Baker, K. (2013). Information Literacy and Cultural Heritage: Developing a model for lifelong learning. Burlington: Elsevier Science.

Borowiecki, K. J., \& T. Navarrete (2017). Digitization of Heritage Collections as Indicator of Innovation. Economics of Innovation and New Technology, 26, 3, 227-246.

Brighton \& Hove City Council (2017). Royal Pavilion \& Museums Interim Forward Plan 2017-20. Brighton. Available from: http://brightonmuseums.org.uk/wp-content/uploads/2014/12/RPMInterim-Forward-plan-17-20.pdf

Buchanan, J., Anderson, P., \& G. Power (2017). 'Skills Ecosystems'. In C. Warhurst, K. Mayhew, D. Finegold, \& J. Buchanan (eds.), The Oxford Handbook of Skills and Training. Oxford: Oxford University Press, 444-465.

Buchanan, J., Schofield, K., Briggs, C., Considine, G., Hager, P., Hawke, O., Kitay, J., Meagher, J., Mounier, A., \& S. Ryan (2001). Beyond Flexibility: Skills and work in the future. Sydney: New South Wales Board of Vocational Education and Training. Available from:

https://www.skillsboard.nsw.gov.au/sites/default/files/beyondflex.pdf

Cameron, F., \& S. Kenderdine (eds.) (2006). Theorizing Digital Cultural Heritage: A critical discourse. Cambridge, Mass. \& London: MIT.

Ch'ng, E., Gaffney, V., \& H. Chapman (eds.) (2013). Visual Heritage in the Digital Age, Spring Series on Cultural Computing. London: Springer-Verlag.

Charitonos, K., Blake, C., Scanlon, E., \& A. Jones (2012). Museum Learning via Social and Mobile Technologies: (How) can online interactions enhance the visitor experience? British Journal of Educational Technology, 43, 5, 802-819.

Cho, C.-W., Yeh, T.-K., Cheng, S.-W., \& C.-Y. Chang (2012). The Searching Effectiveness of Social Tagging in Museum Websites. Journal of Educational Technology \& Society, 15, 4, 126.

Creative and Cultural Skills (2011). Sector Skills Assessment for the Creative Industries of the UK. London: Creative and Cultural Skills. Available from:

https://creativeskillset.org/assets/0000/6023/Sector Skills Assessment for the Creative Industries - Skillset and CCSkills 2011.pdf

Davies, M. (2007). The Tomorrow People: Entry to the museum workforce. Report to the Museums Association and the University of East Anglia. London: Museums Association. Available from: https://www. museumsassociation.org/download?id=13718

DCMS (Department for Digital, Culture, Media \& Sport) (2018). Culture is Digital: Executive summary. London: DCMS. Available from:

https://www.gov.uk/government/uploads/system/uploads/attachment data/file/686725/Culture is Digital Executive summary $1 . \mathrm{pdf}$ 
Derby Museums (2014a). Digital Engagement Strategy. Derby. Available from:

https://www.derbymuseums.org/wp-content/uploads/2017/02/Derby-Museums-Digital-

Engagement.pdf

Derby Museums (2014b). Social Media Strategy. Derby: Derby Museums. Available from:

https://www.derbymuseums.org/wp-content/uploads/2017/02/Derby-Museums-Social-Media-

Strategy-single-pages.pdf

Derby Museums (2017a). Derby Museums Annual Review 2016-2017. Derby: Derby Museums. Available from: https://www.derbymuseums.org/wp-content/uploads/2017/12/0333 DerbyMuseums-Annual-Review-2016-17 digital.pdf

Derby Museums (2017b). Derby Museums - Digital Policy and Plan 2018-22 (internal document). Derby: Derby Museums.

Derby Museums (2017c). Human-centred Design \& Co-production Handbook. Derby. Available from: https://www.derbymuseums.org/resources/derby-museums-human-centred-design

Donghui, C., Guanfa, L., Wensheng, Z., Qiyuan, L., Shuping, B., \& L. Xiaokang (2017). Virtual Reality Technology Applied in Digitalization of Cultural Heritage. Cluster Computing, 1-12.

Drotner, K., \& K. C. Schrøder (eds.) (2013). Museum Communication and Social Media: The connected museum. New York and Abingdon: Routledge.

Edmundson, A. (2015). Curating in the Postdigital Age. M/C Journal 18, 4. Consulted 30 January 2018. Available from: http://journal.media-culture.org.au/index.php/mcjournal/article/viewArticle/1016

Finegold, D. (1999). Creating Self-sustaining, High-skill Ecosystems. Oxford Review of Economic Policy, $15,1,60-81$.

Finnis, J., Chan, S., \& R. Clements (2011). How to evaluate online success? A new piece of action research. MW2011: Museums and the Web 2011. Published 31 March 2011. Available from: https://www.museumsandtheweb.com/mw2011/papers/how to evaluate online success a new p iece of .html

Fulton, B., Botticelli, P., \& J. Bradley (2011). Digln: A hands-on approach to a digital curation curriculum for professional development. Journal of Education for Library and Information Science, 52, 2, 95-109.

Garibaldi, R. (2015). The Use of Web 2.0 Tools by Italian Contemporary Art Museums. Museum Management and Curatorship (Online), 30, 3, 230-243.

Goss, S. (2016). The Future for GLAM Sector Professionals. Archifacts, 63, 63.

Howard, K. (2013). GLAM (Re-)Convergence and the Education of Information Professionals. Paper presented at A GLAMorous Future? Reflecting on Integrative Practice Between Galleries, Libraries, Archives and Museums. Victoria University, Wellington, New Zealand.

Hutchinson, F. C., \& C. Cartmell (2016). Opening Up Entry Routes to Our Sector: Reflections on Museums Galleries Scotland's internship programme. Museum International 68, 269-270, 97-111.

James, D. (2015). How to be a Digital Leader and Advocate: The changing role of the digital department. MW2015: Museums and the Web 2015. Published 30 January 2015. Available from: https://mw2015.museumsandtheweb.com/paper/how-to-be-a-digital-leader-and-advocate-thechanging-role-of-the-digital-department/

Jeonghyun, K., Warga, E., \& W. E. Moen (2013). Competencies Required for Digital Curation: An analysis of job advertisements. The International Journal of Digital Curation, 8, 1, 66-83.

Jisc (2014). Developing Digital Literacies (online guide). Bristol: Jisc. Available from:

https://www.jisc.ac.uk/guides/developing-digital-literacies 
Kelly, L. (2016). The (Post) Digital Visitor: What has (almost) twenty years of museum audience research revealed? MW2016: Museums and the Web 2016. Published 16 February 2016. Available from: https://mw2016.museumsandtheweb.com/paper/the-post-digital-visitor-what-has-almost-20years-of-museum-audience-research-revealed/

Koh, K. \& J. Abbas (2015). Competencies for Information Professionals in Learning Labs and Makerspaces. Journal of Education for Library and Information Science, 56, 2, 114-129.

Kouper, I. (2016). Professional Participation in Digital Curation. Library \& Information Science Research $38,3,212-223$.

Li, Y. C., Liew, A. W. C., \& W. P. Su (2012). The Digital Museum: Challenges and solution. Paper presented at the 2012 8th International Conference on Information Science and Digital Content Technology (ICIDT). Jeju, Korea.

Liritzis, I., Al-Otaibi, F. M., Volonakis, P., \& A. Drivaliari (2015). Digital Technologies and Trends in Cultural Heritage. Mediterranean Archaeology and Archaeometry, 15, 3, 313-332.

Lopez, X., Margapotia, I., Maraglianoa, R., \& G. Boveb (2010). The Presence of Web 2.0 Tools on Museum Websites: A comparative study between England, France, Spain, Italy, and the USA. Museum Management and Curatorship (Online), 25, 2, 235-249.

Madrid, M. M. (2013). A Study of Digital Curator Competences: A survey of experts. International Information and Library Review, 45, 3-4, 149-156.

Marty, P. F. (2007). The Changing Nature of Information Work in Museums. Journal of the American Society for Information Science and Technology 58, 1, 97-107.

Marty, P. F. (2006). Finding the skills for tomorrow: Information literacy and museum information professionals. Museum Management and Curatorship, 21, 4, 317-335.

Matos, A., \& A. Carvalho (2016). 'e-Challenges' for Museum Professionals in Portugal. Paper presented at the 2nd International Conference DC-Me 2: Digital Challenges for Museum Experts, Athens, Greece.

McKenzie, B., \& N. Poole (2011). Mapping the Use of Digital Technologies in the Heritage Sector. London: Flow/Collections Trust.

Melting Pro. (2017). Museum Professionals in the Digital Era: Agents of change and innovation. Bologna: MuSA: Museum Sector Alliance Project. Available from: http://www.project-musa.eu/wpcontent/uploads/2017/03/MuSA-Museum-professionals-in-the-digital-era-short-version.pdf

Moore, C. (2015). Embracing Change: Museum educators in the digital age. Journal of Museum Education, 40, 2, 141-146.

MU.Sa Project. (2017). Museum Professionals in the Digital Era: Agents of change and innovation. Rome: Mu.Sa Project. Available from: http://www.project-musa.eu/wpcontent/uploads/2017/03/MuSA-Museum-professionals-in-the-digital-era-full-version.pdf

National Army Museum (2017a). Digital Strategy (internal document). London: National Army Museum.

National Army Museum (2017b). Trustees Report and Report of Council, Year Ended 31 March 2017. London: National Army Museum. Available from:

https://www.nam.ac.uk/sites/default/files/attachments/accounts-16-17.pdf

National Museums Scotland (2016). Shaping the Future: Strategic plan 2016-2020. Edinburgh: National Museums Scotland. Available from: https://www.nms.ac.uk/media/1151246/nms-strategicplan-2016-20-shaping-the-future.pdf 
National Museums Scotland (2013). Digital Media Strategy and Plan 2013-17. Edinburgh: National Museums Scotland.

Nesta \& ACE (2017). Digital Culture 2017. London: Nesta and Arts Council England. Available from: https://www.nesta.org.uk/sites/default/files/digital culture 2017.pdf

Nesta, AHRC, \& ACE (2015). Digital Culture 2015: How arts and cultural organisations in England use technology. London: Nesta, Arts \& Humanities Research Council, Arts Council England. Available from: http://www.artscouncil.org.uk/sites/default/files/download-file/Digital-Culture-2015-Final.pdf

Nesta, AHRC, \& ACE (2014). Digital Culture 2014: How arts and cultural organisations in England use technology. London: Nesta, Arts \& Humanities Research Council, Arts Council England. Available from: http://www.artscouncil.org.uk/sites/default/files/download-file/Digital-Culture-2014-ResearchReport2.pdf

NMC (New Media Consortium)(2015). NMC Horizon Report: 2015 museum edition. Available from: https://www.nmc.org/publication/nmc-horizon-report-2015-museum-edition/

NMC (New Media Consortium)(2016). NMC Horizon Report: 2016 museum edition. Available from: https://www.nmc.org/publication/nmc-horizon-report-2016-museum-edition/

OECD/ILO (2017). Better Use of Skills in the Workplace: Why it matters for productivity and local jobs. Paris: OECD Publishing.

Owens, T. (2013). Digital Cultural Heritage and the Crowd. Curator: The Museum Journal, 56, 1, 121130.

Parry, R. (2005). Digital Heritage and the Rise of Theory in Museum Computing. Museum Management and Curatorship 20, 4, 333-348.

Parry, R. (2007). Re-coding the Museum: Digital heritage and the technologies of change. London and New York: Routledge.

Parry, R. (ed.) (2010). Museums in a Digital Age. Abingdon and New York: Routledge.

Parry, R. (2013). The End of the Beginning: Normativity in the postdigital museum. Museum Worlds, 1, 24-39. Pedro, A. R. (2010). Portuguese Museums and Web 2.0. [Os museus portugueses e a Web 2.0]. Ciencia da Informacao, 39, 2, 92-100.

Proctor, N. (2010). Digital: Museum as platform, curator as champion, in the age of social media. Curator: The Museum Journal, 53, 1, 35-43.

Ray, J. (2017). Digital Curation in Museums. Library Hi Tech, 35, 1, 32-39.

Redman, J. (2007). Advances in Digital Imaging for Fine Art and Cultural Heritage. Paper presented at the 23rd International Conference on Digital Printing Technologies 2007 (NIP 23): Digital Fabrication, Anchorage, Alaska, USA.

Ridge, M. (2014). Crowdsourcing Our Cultural Heritage. Farnham: Ashgate.

Royal Pavilion \& Museums, Brighton and Hove (2017a). Royal Pavilion \& Museums Manifesto for the $21^{\text {st }}$ Century. Brighton: Royal Pavilion \& Museums. Available from:

http://brightonmuseums.org.uk/wp-content/uploads/2017/05/RPM Manifesto Feb2017.pdf

Royal Pavilion \& Museums, Brighton and Hove (2017b). Digital Policy 2018-22 (Draft 0.4). Internal document. Brighton: Royal Pavilion \& Museums.

Schroer, C. (2012). Advanced Imaging Tools for Museum and Library Conservation and Research. Bulletin of the American Society for Information Science and Technology, 38, 2, 38-42.

Shipp, J. N. (2016). Do I Really Need Specialist Qualifications to Work as a Professional in a Gallery, Library, Archive or Museum? Australian Library Journal, 65, 4, 280-287. 
Stack, J. (2013). Tate Digital Strategy 2013-15: Digital as a dimension of everything. Tate Papers no. 19. Available from: http://www.tate.org.uk/research/publications/tate-papers/19/tate-digitalstrategy-2013-15-digital-as-a-dimension-of-everything

Suzić, B., Karlíček, M., \& V. Stříteský, (2016). Social Media Engagement of Berlin and Prague Museums. The Journal of Arts Management, Law, and Society, 46, 2, 73-87.

Tallon, L. (2017). Digital is More Than a Department, it is a Collective Responsibility. The Met. Published 24 October 2017. Available from: https://www.metmuseum.org/blogs/now-at-themet/2017/digital-future-at-the-met

Tallon, L. \& K. Walker (eds.) (2008). Digital Technologies and the Museum Experience: Handheld guides and other media. Lanham, US: Alta Mira Press.

Tammaro, A. M., Madrid, M., \& V. Casarosa, (2013). 'Digital curators' education: Professional identity vs. convergence of LAM (Libraries, Archives, Museums)'. In M. Agosti, F. Esposito, S. Ferilli, \& N. Ferro (eds.), Digital Libraries and Archives (8th Italian Research Conference, IRCDL 2012 Bari, Italy, February 9-10, 2012 Revised Selected Papers) (Vol. 354). Heidelberg: Springer, 184-194

Tibbo, H. R., \& C. A . Lee (2012a). Convergence through Capabilities: Digital curation education for libraries, archives and museums. Archiving Conference, 1, 53-57.

Tibbo, H. R. \& C. A. Lee (2012b). Closing the Digital Curation Gap: A grounded framework for providing guidance and education in digital curation. Paper presented at the Archiving 2012 - Preservation Strategies and Imaging Technologies for Cultural Heritage Institutions and Memory Organizations, Final Program and Proceedings.

Tibbo, H. R., \& C. A . Lee (2010). Convergence through Capabilities: Digital curation education for libraries, archives and museums. Archiving Conference, 1, 53-57.

Tsolis, D., Sioutas, S., Xenos, M. N., \& G. Styliaras (2011). Copyright and IPR Management for Cultural Heritage Digital Content in Peer-to-peer Networks. Journal of Cultural Heritage, 12, 4, 466-475.

Verboom, J., \& P. Arora (2013). Museum 2.0: A study into the culture of expertise within the museum blogosphere. First Monday, 18, 8.

Visser, J. (2013). A Job Description for Future Museum Professionals. The Museum of the Future, January 21, 2013. Available from: http://themuseumofthefuture.com/2013/01/21/a-job-descriptionfor-future-museum-professionals

Wellington, S., \& G. Oliver (2015). 'Reviewing the Digital Heritage Landscape: The intersection of digital media and museum practice'. In S. Macdonald, \& H. Rees Leahy (eds.), The International Handbooks of Museum Studies (Vol. 1). New Jersey: John Wiley \& Sons, 577-598.

Welsh, P. H. (2013). Preparing a New Generation: Thoughts on contemporary museum studies training. Museum Management and Curatorship, 28, 5, 436-454.

White, H. (2016). The Goal Posts Have Moved: The implications of new paradigms for professional skills in museums. Museum International, 68, 1-2, 71-80.

Windsor, K. \& C. Alcorso (2008). Skills in Context: A guide to the skill ecosystem approach to workforce development. Sydney: Department of Education and Training (DET)/Department of Education, Employment and Workplace Relations (DEEWR).

Yoon, S. A., Elinich, K., Wang, J., Steinmeier, C., \& S. Tucker (2012). Using Augmented Reality and Knowledge-building Scaffolds to Improve Learning in a Science Museum. International Journal of Computer-Supported Collaborative Learning, 7, 4, 519-541.

Younan, S. (2015). Poaching Museum Collections Using Digital 3D Technologies. Journal of Science and Technology of the Arts, 7, 2, 25-32. 


\section{$\mathbf{8}$ Case study museums}

\section{Amgueddfa Cymru - National Museum Wales}

Amgueddfa Cymru - National Museum of Wales (AC-NMW) is dedicated to preserving, presenting and promoting the culture of Wales. The national museums body comprises seven museums: National Museum Cardiff; St Fagans National Museum of History (Cardiff); National Waterfront Museum (Swansea); Big Pit National Coal Museum (Blaenavon); National Slate Museum (Llanberis); National Roman Legion Museum (Caerleon); and National Wool Museum (Dre-fach Felindre).

The Museum employs 600 staff and has a lively volunteer programme - volunteers contributed over 25,500 hours of work during $2016 / 17$. The Museum has developed skills development placements for people with additional needs such as Down's syndrome and autism; in turn these volunteers have enriched the Museum's offer to the public.

The Museum has around 200,000 fans and followers on its Facebook and Twitter profiles.

The Museum's current operational plan discusses the website as the Museum's eighth public site and one of the five priorities that guide the work of the Museum focuses explicitly on the 'digital experience'. All parts of the website and the Museum's social media channels are bilingual Welsh and English.

Recent and current 'digital projects' at the Museum include:

- As part of the $£ 30$ million transformation of St Fagans National Museum of History, delivering a number of opportunities for engagement in gallery and on site, for example a free bilingual storytelling app created for visitors;

- An online collections search that provides information on more than 500,000 of its objects;

- The design and development of in-gallery content and interactives for an annual programme of exhibitions;

- Delivering the People's Collection Wales programme with other strategic heritage partners;

- Working in partnership with Google to develop and publish a virtual reality expedition (Big Pit National Coal Museum); and

- The development of the visitor experience strategy that will improve visitors' experience at the museums including digital interactivity.

AC-NMW formulated a Digital Content Strategy 2014-17, which includes the following five objectives:

- Increase the digital content output;

- Provide collections information in an open and accessible way;

- Increase digital participation and online communities;

- Build on their user-centric approach to design and technology; and

- Deliver a digital transformation for AC-NMW. (Amgueddfa Cymru - National Museum of Wales, 2014) 
Digital transformation is conceptualised in the strategy as follows:

- Embedding digital thinking into everything the museum does;

- Boosting understanding of digital in the museum through understanding how staff use digital media and how they want to use it; and

- Considering how it meets the needs of users.

The role of the Digital Media Department is also discussed in the strategy: it is proposed that the department will move beyond delivering projects to become leaders and trainers in the use of digital tools and promote emerging media, while ensuring that the current staff of the department work more efficiently.

Sources: Amgueddfa Cymru - National Museum Wales website (2017), Amgueddfa Cymru - National Museum of Wales (2014)

\section{Derby Museums Trust}

Derby Museums comprises: the Museum and Art Gallery; the Silk Mill; and Pickford's House. The Museum and Art Gallery has longstanding and temporary exhibits with minimal digital interactives or displays. The Silk Mill is due to open in summer 2020 and is currently undergoing redevelopment, supported by the Heritage Lottery Fund, Derby City Council, D2N2, Arts Council England and a number of other trusts and foundations. Pickford's House showcases aspects of domestic life from the 18th to the 20th centuries. Derby Museums also run its website at https://www.derbymuseums.org with additional information on the sites, exhibits, 360-degree tours, news and events, learning resources and so on. Derby Museums has a collection of over 250,000 objects which it cares for on behalf of Derby City Council.

Derby Museums became an independent charity in 2012. It is a charitable trust with funding from Arts Council England and Derby City Council. Funding has also been committed in the form of a Heritage Endowment Grant by the Heritage Lottery Fund, which Derby Museums aims to match-fund to create an Endowment Fund that will be built on to secure the long-term future of Derby Museums. Funding also comes from donations from individuals, and community and corporate supporters. Derby Museums' purpose is stated as:

'Derby Museums is for the thinker and maker in all of us.

Together we make museums for the head, heart and hands. We will do this by:

- Being independent;

- Fostering a spirit of experimentation;

- Pursuing mutual relationships;

- Creating the conditions for well-being (helping people connect with others, keep learning, take notice of the world and give back to the community); and

- Proving that we are doing it.' (Derby Museums website, 2017)

Derby Museums' Annual Review 2016-2017 (Derby Museums, 2017a) reported that the museums had received 124,111 visitors, up by 10 per cent from the previous year. The number of hours donated by volunteers had increased 58 per cent, people participating in informal learning activities by 41 per cent and visits made by schoolchildren were up by 30 per cent.

Derby Museums has three documents that set out its digital plans for the future. First, the Digital Engagement Strategy (Derby Museums, 2014a) which defines Derby Museums' strategy to share its 
collections online, develop products and services and increase its profile through engagement. This sets out:

- Creating a clear online brand for Derby Museums;

- Engaging with local communities as well as geographically dispersed audiences;

- Unifying databases for collections and images;

- Developing an accessible and searchable website;

- Ensuring videos are a part of the digital offer; and

- Creating digital conversations through social media, blogs, etc.

The digital ethos of Derby Museums is:

by making the most of all that digital can offer, Derby Museums commits to showcasing its offerings, its expertise and its benefits to the full range of stakeholders. By marrying up the passion, energy and commitment of the wonderful staff, the amazing stories, heritage and collections and the fantastic tools and techniques digital offers, Derby Museums can promote and present the venues and the region in an open, honest, straightforward and all-encompassing way. (Derby Museums, 2014a, p. 48)

Engagement is a key part of the Derby Museums strategy, which is not led by digital tools and technology. They have taken inspiration for their digital engagement activity from museums across the world, including, for example, the Victoria and Albert Museum, the Bristol Arc project, 9/11 Memorial Museum, New York Botanical Garden, the Metropolitan Museum of Art, and the Smithsonian Institution.

Second, the Social Media Strategy (Derby Museums, 2014b) sets out Derby Museums' approach and aims of using social media as a tool to attract visitors and showcase the museums. Social media was seen as part of the wider Derby Museums' marketing strategy. Tools noted as part of the strategy included Twitter, Facebook, Instagram and Vine. The quality of content is viewed as important to successful engagement with social media with the overall aim to provide a service for followers that is engaging and interesting. It was noted that different content is needed for different channels. The strategy sets out: how content will be optimised; the tone of content; use of images; timing; management and monitoring of social media accounts; and promotion.

Third, the Digital Policy and Plan 2018-22 (Derby Museums, 2017b); an internal document shared with the research team. The policy sets out the Derby Museums' key achievements since the publication of the Digital Engagement Strategy and Social Media Strategy, including:

- 'Established a high social media profile on Twitter, Facebook, Instagram and Tumblr;

- Created a new website that is more accessible, with better navigation and easier to update,

- Implemented free high-speed wireless access at all our Museum sites;

- Engaged and upskilled staff and volunteers in the use of social media and digital communication:

- Increased staff resources for digital communications;

- Purchased a new Collections Management System and embarked upon an ongoing programme of digitising Collections of Making and Social History; 
- Embedded digital interpretation into the plans for the redevelopment of the new Museum of Making;

- Experimented with digital engagement projects linked to social media;

- Experimented with digital making projects on site at the Silk Mill.' (Derby Museums, 2017b, p. 1)

The policy also outlines some of the challenges, such as ensuring digital is integral to the museums and staff are skilled and keeping up to date with technology.

Sources: Derby Museums Trust website (2017), Derby Museums (2017a, 2017b, 2017c)

\section{Museum of London}

The Museum of London tells the story of London and Londoners from prehistoric times to the present day. The museum has three sites: the Museum of London at London Wall in the City; the Museum of London Docklands at Canary Wharf; and the Archaeological Archive in Hackney (the largest of its kind in the world). The Museum of London is moving to a new site in West Smithfield that is due to open in 2023. The museum has 255 employees and more than 300 volunteers.

In the year 2016/17 over a million visits were made to the museum as a whole and there were almost two million web sessions and over 135,000 Facebook likes. The museum has over 100,000 followers on Twitter and 27,000 followers on Instagram.

Recent and current 'digital' projects include:

- The complete redesign of its website in 2016.

- The introduction of a customer relations management system, which has enabled the museum to integrate all marketing databases onto a single platform and integrate this with the ticketing system and the website. The new system has also improved the museum's ability to send targeted communications to customers through social media channels.

- The introduction of new booking and resource management systems for its public programmes (2017).

- A new 'Great Fire of London' website and a Great Fire Minecraft game, produced in 2016. The museum also delivered a live streamed event on the theme of the Great Fire that simultaneously reached 30 schools in the UK, and it continues to pilot different approaches to live streaming.

- The \#LondonView project, which invites people to share photos and posts on social media that show how they see London. The posts are collected, curated and played back, sharing different views of the city.

Plans for the immediate future include the introduction of a digital asset management system. Looking further ahead, the New Museum project has brought the issue of developing a long-term vision for digital into sharp focus.

Source: Museum of London website (2017)

\section{National Army Museum}

The National Army Museum has recently moved back into a purpose-built building in Chelsea, which houses five galleries and aims to attract around 260,000 visitors per year. A second site in Stevenage houses the collections. The National Army Museum 'examine[s] the army's role as protector, aggressor and peacekeeper from the British Civil Wars to the modern day' and aims to be a 'first class 
museum that moves, inspires, challenges, educates and entertains'. The National Army Museum fulfils a research role as well as acting in a public-facing, engaging and educating capacity. It understands itself as a family museum with a deliberately broad remit to engage well beyond those who have direct connections or affinity with the army. Its objectives are set out in The National Army Museum's Royal Charter, first granted in 1960. The museum is mainly funded through an annual Grant-in-Aid (GiA) from the Ministry of Defence. The museum's 2016/17 budget was $£ 7.10$ million, of which $\mathrm{f6.03}$ million was a GiA from the Ministry of Defence. The museum expects levels of selfgenerated monies to rise in the refurbished Chelsea location through other activities such as venue hire.

The Trustees Report and Report of Council, Year Ended 31 March 2017 refers to five key strategic objectives:

- Creative memorable, relevant and accessible activities aligned to audience need in order to maximise audiences and generate footfall;

- Establish the National Army Museum, nationally and internationally, as the first choice for the history and life of the British Army;

- Maximise financial resilience, organisational efficiency and sustainability;

- Safeguard and make accessible the collections and associated knowledge; and

- Develop a national footprint by establishing a network of partnerships, linkages and working relationships.

The National Army Museum has 70-80 full-time equivalent staff split across the divisions Collections and Engagement, Operations (including facilities and IT infrastructure), Development (fundraising, marketing and digital) and Human Resources.

The museum produced a draft Digital Strategy paper in 2017(National Army Museum, 2017a); this was shared with the research team. This includes a vision, which focuses on the following three key areas:

- Engagement with audiences;

- Integrating digital into all aspects of the museum's projects and activities; and

- Developing staff skills to fulfil the digital aspects of their roles.

The draft strategy states that digital must be factored into recruitment as well as training and development for all members of staff, and that the creation of new specialist roles may be required to enable further digital development of the museum. It proposes that a cross-divisional, crosshierarchical Digital Working Group should be established, a group that would:

[...] provide an approachable forum for all staff to propose ideas and projects for consideration [...] a platform for informed discussion; and draw on its members for researched, practical solutions to real-world problems. (National Army Museum, 2017a, p 7)

Source: National Army Museum website (2017), National Army Museum (2017a, 2017b)

\section{National Museums Scotland}

National Museums Scotland comprises multidisciplinary collections across four museum sites:

- National Museum of Scotland on Chambers Street in Edinburgh;

- National War Museum situated within Edinburgh Castle; 
- National Museum of Flight in East Lothian; and

- National Museum of Rural Life near East Kilbride.

In addition, the National Museums Collection Centre at Granton in north Edinburgh provides a home for the objects and specimens that are not currently on display as well as facilities for undertaking collections research and conservation.

National Museums Scotland has approximately 450 staff and over 500 volunteers. Its principal funding sources are: Grant-in-Aid, received annually from the Scottish Government; income from museum, exhibition and events admissions, retail, catering and venue hire; and grants, sponsorship and philanthropic donations. Non-governmental income has more than tripled over the last decade, to $£ 17$ million per annum, with more than $£ 100$ million raised from public and private sources. The museum is finalising the delivery of an $£ 80$ million masterplan to transform the National Museum of Scotland, which has established the museum as the UK's most visited outside London, and increased NMS's international reputation. Visitor numbers for National Museums Scotland overall have nearly doubled in the last decade, to 3.1 million visitors in 2017.

Transforming its digital engagement is one of seven National Museums Scotland's priorities. Specifically, the museum aims to:

- Embed digital thinking across the organisation, investing in versatile technologies, digital asset management and skills development;

- Increase collections information online and build platforms to share expertise, focusing on user needs, attracting larger audiences, encouraging debate and supporting learning; and

- Integrate high-quality digital experiences into our Museums, enriching exhibitions, displays and events to increase engagement with collections.

National Museums Scotland has formulated a Digital Media Strategy and Plan 2013-17 which aims to:

- Exploit digital approaches and technology to increase access to collections (Audiences);

- Create inspiring and memorable visitor experiences (Audiences);

- Enable more participation and dialogue with a broader range of audiences (Audiences;)

- Enable greater access to objects, information and expertise (Collections);

- Extend the reach of our collections within and outside Scotland (Connections); and

- Lead and develop people to realise their potential (People and Resources).

Source: National Museums Scotland (2013)

This strategy followed from earlier work that had led to the following achievements:

- Delivered a refreshed National Museums Scotland website, and smartphone-optimised site;

- Almost doubled the number of visits to our website, and focused on delivering improved information on exhibitions and events in particular;

- Opened up public access to our own collections database for the first time with over 20,000 object records available online;

- Grown our presence on key social networks with one of the largest follower bases in the Scottish cultural scene and healthy rates of engagement; 
- Continued to develop 'niche' digital content for a number of audiences, including a lively behind-the-scenes blog, online games and in-depth information on new acquisitions; and

- Undertaken a number of informative projects using mobile technology, including the Museum Explorer, and soon to be published Museum Highlights and Capture the Museum apps.

A new digital media strategy is currently being prepared for the period 2018-2022.

Source: National Museums Scotland (2016), National Museums Scotland website (2017)

\section{Royal Pavilion and Museums Brighton and Hove}

Royal Pavilion and Museums Brighton and Hove (RPMBH) comprises: the Royal Pavilion; Brighton Museum and Art Gallery; the Booth Museum of Natural History; Hove Museum and Art Gallery; and Preston Manor. The museum's website (https://brightonmuseums.org.uk) is viewed as another 'site' forming part of the group. RPMBH also has responsibility for seven listed buildings and monuments, provides advice to volunteer-run museums and heritage organisations, and runs the South East Museum Development Programme. RPMBH is, at the time of writing, run by Brighton and Hove City Council with some funding from Arts Council England and, previously, the Museums, Libraries and Archives Council. In the past, 81 per cent of the income generated by the museum has come from trusts, foundations, grants and individual donations (Brighton and Hove City Council, 2017). Brighton and Hove City Council has been actively exploring options to spin RPMBH out from local authority control since January 2017, but the museum service currently remains with the Council.

RPMBH's mission is:

to use our unique collections, buildings and knowledge to connect people to the past and help them understand the present in order to positively incidence the future. (RPMBH website, 2017)

The Royal Pavilion \& Museums Manifesto for the 21st Century (Royal Pavilion \& Museums, Brighton and Hove (2017a)) recognises the digital revolution in Brighton, seeing the museum as part of the supporting 'the creation of a socially, environmentally and economically sustainable future' (p. 1). The museum aims to create a learning environment, to be part of a global community embedded in digital innovation. This includes the digitisation of collections and digital publishing ensuring that information can be shared with geographically dispersed audiences.

Brighton and Hove City Council provides human resources, ICT, legal and finance functions for the museum. Across the five sites, there are an estimated 150 staff and around 150 volunteers. Teams across the RPMBH include: curators; conservators; technical; historic building management; learning and community engagement; creative programming; marketing; retail; events and function management; development and fundraising; digital and ICT; visitor services; and support services. The Manifesto for the 21st Century states that the museum is to be run as a 'fellowship' where all staff from across the organisation are able to 'instigate and inspire change'. This is done with great respect for localised and specialist knowledge.

The Royal Pavilion's visitor numbers are increasing, with a target of 100,000 visitors for 2017-2018, which they are on track to meet. The target for all five sites in 2017-2018 is 509,000 visitors. The annual average total visitor numbers have been about 0.5 million since charging was introduced in Brighton Museum.

RPMBH are currently working on a digital policy; an early draft of the policy was shared with the research team. The policy sets out how digital activity will be used to support work and how RPMBH will respond to the challenges presented by evolving technology. At the heart of the policy is the need for digital innovation to be 'sustainable' and 'fit for purpose'. The policy sets out the museum's digital engagement for 2018-2022, which is founded on: 
- Improving and enhancing the visitor/audience experience;

- Changing the way we work with colleagues and partners; and

- Publishing information and knowledge.

(Royal Pavilion \& Museums, Brighton and Hove, 2017b, p. 3).

The policy states that successful use of digital media is shaped by the quality of images, information, etc. and how audiences are engaged through, for example, learning, commercial activity and coproduction.

Source: Brighton and Hove City Council (2017), Royal Pavilion and Museums Brighton and Hove website (2017)

\section{Independent museums}

Independent museums and galleries are social enterprises that make up more than half of all museums in the UK, with at least 1,600 independent museums and galleries. The independent sector includes a wide range of types of museums with two thirds dealing with specialist subjects; among these transport, military, industrial heritage and famous people are the most numerous. A third are more general in their collections and range from major 'civic' museums to numerous medium size museums in county towns and over 300 small museums concerned with local and community history.

Source: Association of Independent Museums website (2017), https://www.aimmuseums.co.uk/about-independent-museums

The development of digital skills and literacies in small museums is supported by the Arts Council England-funded Museum Development Network that runs regionally specific programmes, many of which have a digital focus.

Source: Museum Development Network website (2017), http://museumdevelopmentnetwork.org/regional-programmes/ 


\section{One by \\ building digitally confident museums}

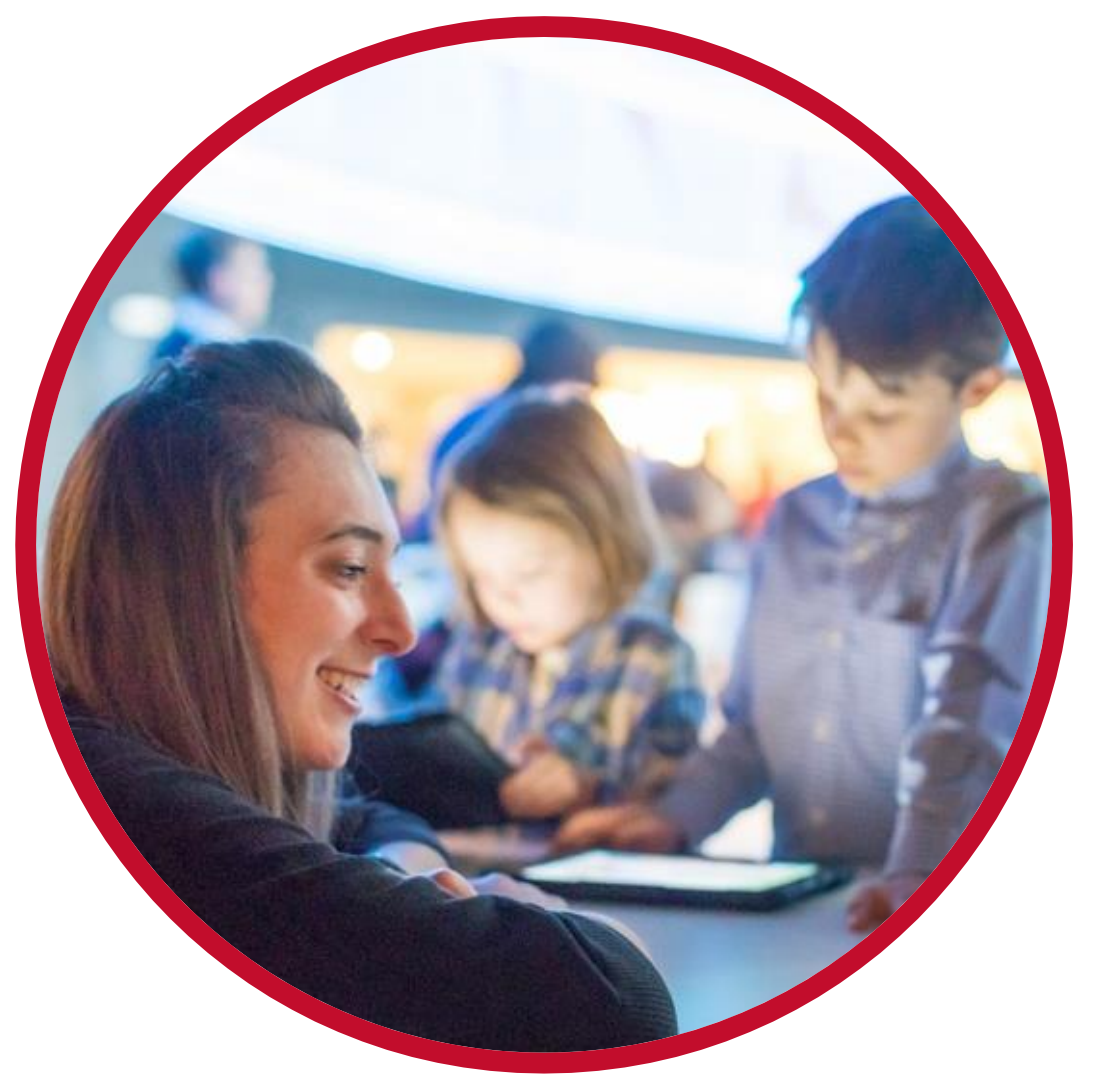

one-by-one.uk • 